ARTICLE

https://doi.org/10.1038/s41467-020-20262-5

\title{
Structure of human RNA polymerase III
}

\author{
Ewan Phillip Ramsay ${ }^{1,5}$, Guillermo Abascal-Palacios ${ }^{1,5}$, Julia L. Daiß2,5, Helen King ${ }^{1}$, Jerome Gouge ${ }^{1}$

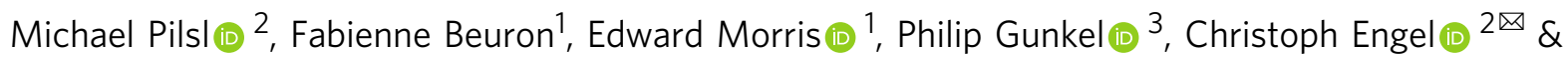 \\ Alessandro Vannini (iD) ${ }^{1,4 凶}$
}

In eukaryotes, RNA Polymerase (Pol) III is specialized for the transcription of tRNAs and other short, untranslated RNAs. Pol III is a determinant of cellular growth and lifespan across eukaryotes. Upregulation of Pol III transcription is observed in cancer and causative Pol III mutations have been described in neurodevelopmental disorders and hypersensitivity to viral infection. Here, we report a cryo-EM reconstruction at $4.0 \AA$ of human Pol III, allowing mapping and rationalization of reported genetic mutations. Mutations causing neurodevelopmental defects cluster in hotspots affecting Pol III stability and/or biogenesis, whereas mutations affecting viral sensing are located in proximity to DNA binding regions, suggesting an impairment of Pol III cytosolic viral DNA-sensing. Integrating x-ray crystallography and SAXS, we also describe the structure of the higher eukaryote specific RPC5 C-terminal extension. Surprisingly, experiments in living cells highlight a role for this module in the assembly and stability of human Pol III.

\footnotetext{
${ }^{1}$ Division of Structural Biology, The Institute of Cancer Research, London SW7 3RP, UK. ${ }^{2}$ Regensburg Center for Biochemistry, University of Regensburg, 93053 Regensburg, Germany. ${ }^{3}$ Max Planck Institute for Biophysical Chemistry, Research Group Nuclear Architecture, 37077 Göttingen, Germany.

${ }^{4}$ Fondazione Human Technopole, Structural Biology Research Centre, 20157 Milan, Italy. ${ }^{5}$ These authors contributed equally: Ewan Phillip Ramsay, Guillermo Abascal-Palacios, Julia L. Daiß. ${ }^{凶}$ email: christoph.engel@ur.de; alessandro.vannini@fht.org
} 
$\mathrm{T}$ ranscription of the eukaryotic genome is mediated by three highly specialized nuclear RNA polymerase ( $\mathrm{Pol}$ ) enzymes. Pol III transcribes short untranslated RNAs, which are essential for cellular functions, such as the entire pool of transfer RNAs, the precursor of the 5S ribosomal RNA and the U6 spliceosomal RNA ${ }^{1}$.

Pol III is a multi-subunit complex composed of 17 subunits. A central ten-subunit core, which harbours the catalytic site and a peripheral heterodimeric stalk that are structurally conserved among the three eukaryotic Pols. The TFIIF-like RPC4/5 and the TFIIE-like RPC3/6/7 subcomplexes are Pol III specific and can be regarded as built-in general transcription factors that play a fundamental role in Pol III transcription initiation and termination ${ }^{2-4}$.

Across the eukaryotic kingdom, Pol III displays a high degree of conservation both in terms of subunit composition and sequence homology of the individual components. A notable exception is the subunit RPC5, which in metazoans encompasses a long C-terminal extension (RPC5EXT, $~ 450$ residues long), whose function is currently unknown.

Pol III activity is highly regulated in a cell cycle and cell-typedependent manner ${ }^{5}$, and is a determinant of lifespan in eukaryotes $^{6}$. In recent years, a large number of disease-causing mutations have been assigned to Pol III subunits, with a particular incidence of allele variants that strongly affect the correct development of the central nervous system (CNS), resulting in severe neurodegenerative diseases ${ }^{7-14}$. Furthermore, causative Pol III mutations have also been described in patients affected by hypersensitivity to viral infection ${ }^{15,16}$.

To date, yeast Pol III has been extensively structurally and functionally characterized, while its human counterpart has been left relatively untouched, due to the inherent technical challenges in obtaining yields amenable for structural biology. However, understanding the specific influence of pathological mutations and the role of regulatory elements unique to the human enzyme relies on such structural information. Here, we report the cryogenic electron microscopy (cryo-EM) reconstruction of human Pol III. We further study the enzymes' complete architecture using a structural biology hybrid approach integrating two crystal structures of the human RPC5 C-terminal extension, as well as SAXS data and molecular modelling. Results of our comparative structural analysis rationalize the effect of pathological mutations and yield unexpected insights into Pol III regulation.

\section{Results}

Purification of human RNA Pol III. To obtain a high-resolution structure of human Pol III, we isolated the endogenous complex from HeLa cells. To this end, we employed CRISPR/Cas9 genome editing in human cells to create a homozygous knock-in of a cleavable green fluorescent protein (GFP)-tag at the $\mathrm{C}$ terminus of subunit RPAC1 (shared between Pol I and Pol III) (Fig. 1a). Fractionation experiments followed by immunopurification using an anti-GFP nanobody revealed that Pol III is present in both nuclear and cytoplasmic fractions (Fig. 1b), in agreement with previous reports highlighting a Pol III cytosolic DNA-sensing activity ${ }^{17,18}$. An optimized large-scale purification, including an ion-exchange step to separate Pol I and Pol III, enabled the isolation of active human Pol III (Fig. 1c, d and Supplementary Fig. 1) from total cell extracts with yields and quality amenable for further EM studies.

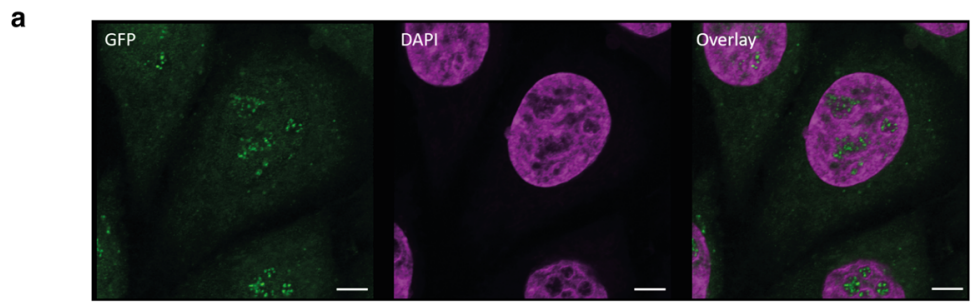

b

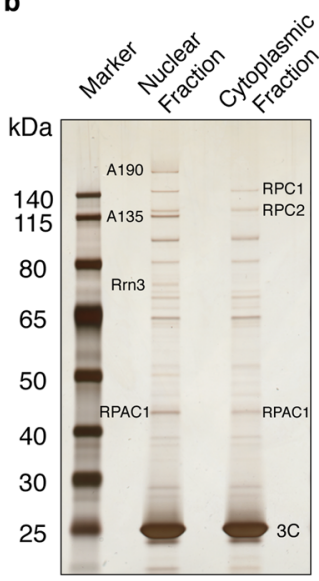

C

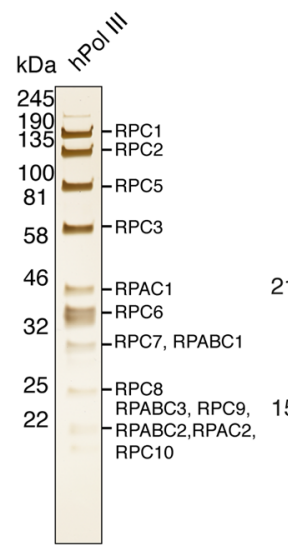

d

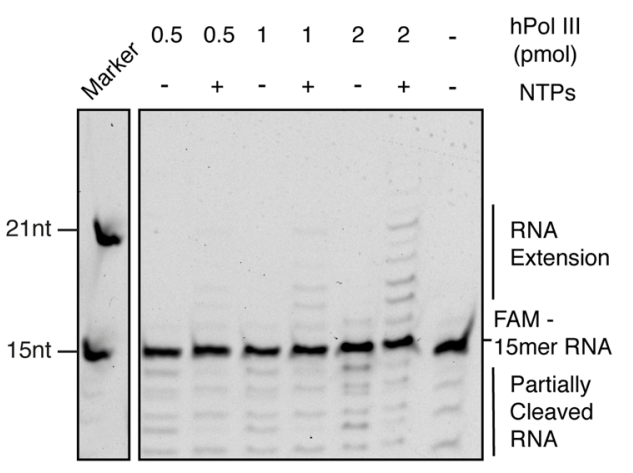

Fig. 1 Purification of GFP-tagged endogenous human RNA polymerase III. a Confocal imaging of modified HeLa cell line expressing homozygous sfGFPtagged POLR1C gene. Endogenous GFP signal, representing Pol I and III (green), DAPI staining (magenta) and overlay of both channels are shown. Scale bar: $5 \mu \mathrm{m}$. Shown is a representative image of four independent experiments. b Affinity-purified human RNA Pol III from HeLa nuclear and cytoplasmic fractions. Confirmed RNA Pol subunits are labelled. Shown is a representative image of two separate experiments. c Purified human RNA Pol III (hPol III) from large-scale whole-cell lysate with Pol III subunits marked. Shown is an excised lane of a representative image of three separate purifications. $\mathbf{d}$ RNA extension assay of fluorescently labelled FAM-15mer RNA primer by purified human Pol III. Marked is Pol III-mediated primer extension. The molecular marker displays expected sizes for 15 and 21 nucleotides (nt). Displayed is a representative image of seven independent repeats. Source data are provided as a Source Data file. 


\begin{tabular}{|c|c|}
\hline \multicolumn{2}{|l|}{ Data collection ( $0^{\circ}$ Tilt) } \\
\hline Voltage $(k V)$ & 300 \\
\hline Electron exposure $\left(\mathrm{e}^{-} / \AA^{2}\right)$ & 44.1 \\
\hline Defocus range $(\mu \mathrm{m})$ & -1.0 to -3.0 \\
\hline Pixel size $(\AA)$ & 1.065 \\
\hline \multicolumn{2}{|l|}{ Data collection ( $30^{\circ}$ Tilt) } \\
\hline Voltage $(\mathrm{kV})$ & 300 \\
\hline Electron exposure $\left(e^{-} / \AA^{2}\right)$ & $37.8,40.6$ \\
\hline Defocus range $(\mu \mathrm{m})$ & -1.2 to -3.0 \\
\hline Pixel size $(\AA)$ & 1.065 \\
\hline \multicolumn{2}{|l|}{ Reconstruction (RELION) } \\
\hline Initial particle images (no.) & 172,678 \\
\hline Final particle images (no.) & 25,369 \\
\hline Map resolution $(\AA)$ & 4.0 \\
\hline FSC threshold & (0.143-thr) \\
\hline Map sharpening $B$ factor $\left(\AA^{2}\right)$ & -116.839 \\
\hline \multicolumn{2}{|l|}{ Model composition } \\
\hline Non-hydrogen atoms & 34,636 \\
\hline Protein residues & 4369 \\
\hline \multicolumn{2}{|l|}{ Refinement (PHENIX) } \\
\hline Map CC & 0.53 \\
\hline \multicolumn{2}{|l|}{ R.m.s. deviations } \\
\hline Bond lengths $(\AA)$ & 0.016 \\
\hline Bond angles $\left(^{\circ}\right)$ & 1.086 \\
\hline \multicolumn{2}{|l|}{ Validation } \\
\hline MolProbity score & 2.74 \\
\hline Clashscore (all-atom) & 31.792 \\
\hline Poor rotamers & 0.0 \\
\hline \multicolumn{2}{|l|}{ Ramachandran plot } \\
\hline Favoured (\%) & 78.66 \\
\hline Allowed (\%) & 20.94 \\
\hline Disallowed (\%) & 0.39 \\
\hline
\end{tabular}

Cryo-EM structure of human Pol III. The non-crosslinked purified human Pol III sample was applied to carbon-coated cryoEM grids and imaged on a Titan Krios TEM microscope equipped with a Falcon III camera. Two data sets were collected at $0^{\circ}$ and $30^{\circ}$ tilting angles, to overcome preferred orientation of the sample on the cryo-grids, resulting in a merged dataset of 172,678 particles after two-dimensional (2D) class averaging (Supplementary Fig. 2 and Table 1). The majority of imaged particles represented the intact 17-subunit human Pol III but a sizeable fraction with a similar angular distribution displayed no density for the RPC3/6/7 heterotrimer, which had possibly dissociated during purification, in agreement with earlier reports ${ }^{19}$, or during cryo-EM specimen preparation. Hierarchical three-dimensional (3D) classification led to a reconstruction of the intact human Pol III from 25,369 particles at an overall resolution of $4.0 \AA$ (Supplementary Figs. 2 and 3 , and Table 1). The core of the enzyme is characterized by a very detailed EM map where side chains are clearly discernible (Fig. 2). The RPC8/9 stalk and the RPC3/6/7 subcomplex are more flexible than the core; hence, their local resolution is lower compared to the rest of the complex (Supplementary Fig. 3). Interestingly, the coiled-coil region of the clamp subdomain within the largest subunit RPC1, which is in direct contact with the RPC3/6/7 heterotrimer, also displays a high degree of flexibility. This finding suggests that the coiled-coil region of the clamp together with the heterotrimer form a discrete structural and functional unit, which in yeast has been shown to be able to sense melting of the upstream side of the transcription bubble ${ }^{4}$.

As can be expected from the high degree of sequence conservation, the overall structure of human Pol III resembles the yeast counterpart. Structure-based alignments and comparison revealed that most subunits share a high degree of similarity and low root-mean-squared deviation values (Supplementary Fig. 4). However, local differences highlight specific features that might be relevant for human-specific regulation and correct assembly of the Pol III enzyme. Three relevant deletions were
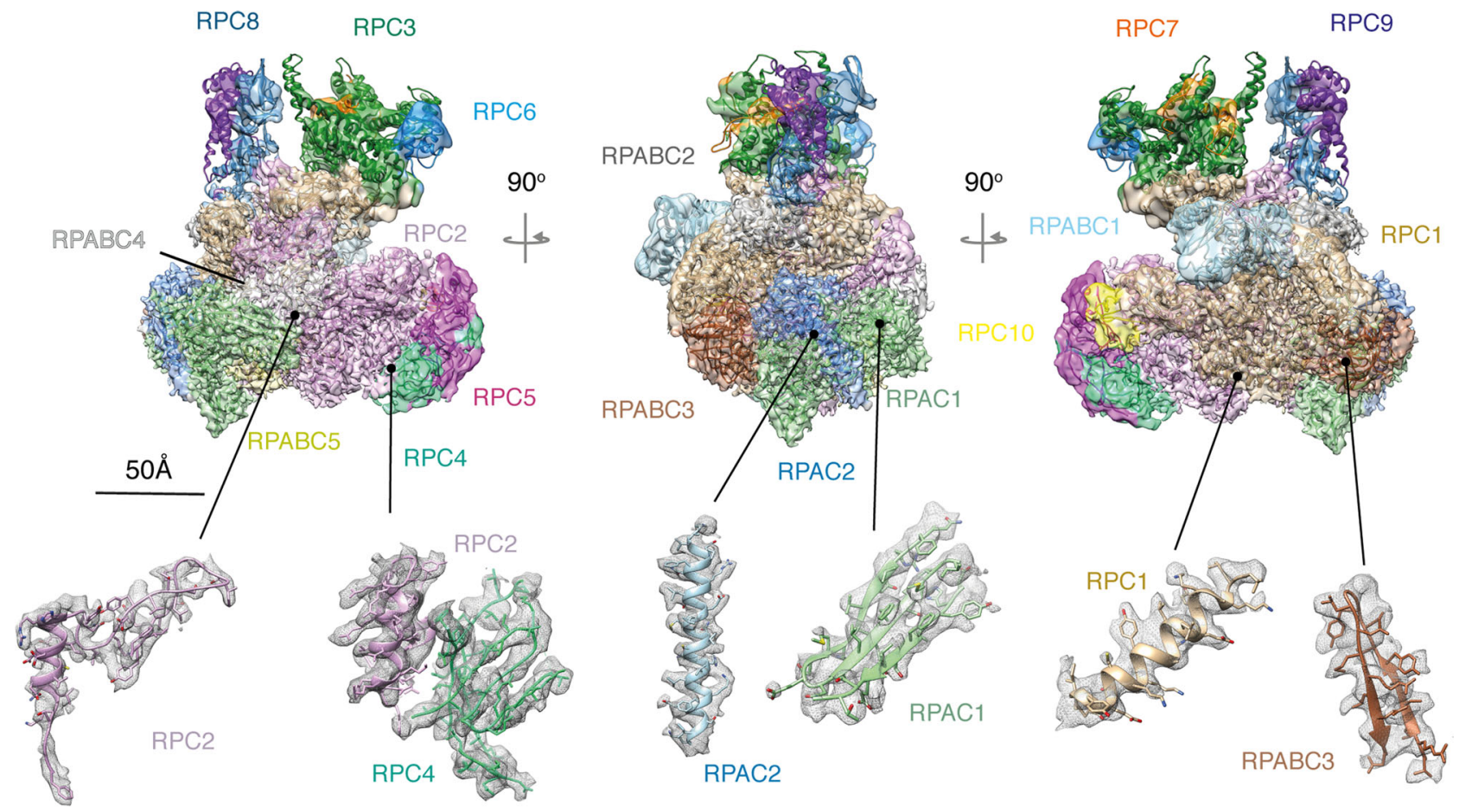

Fig. 2 The structure of human RNA polymerase III. Shown is the electron density map filtered according to the local resolution with the fitted model shown in ribbon representation (above). Regions of the electron density map are coloured according to the subunit structure as labelled. Shown below are selected regions of several subunits showing the fit with the filtered electron density (mesh). 


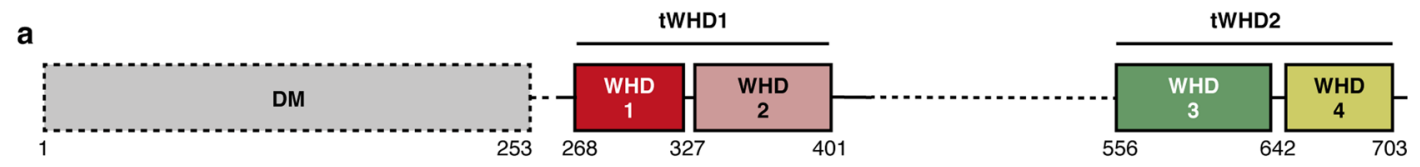

b
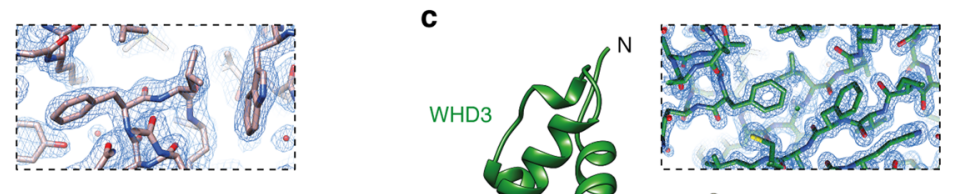

f

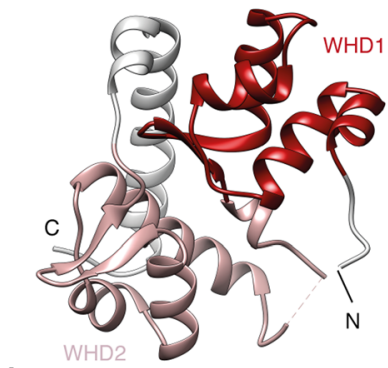

d

e
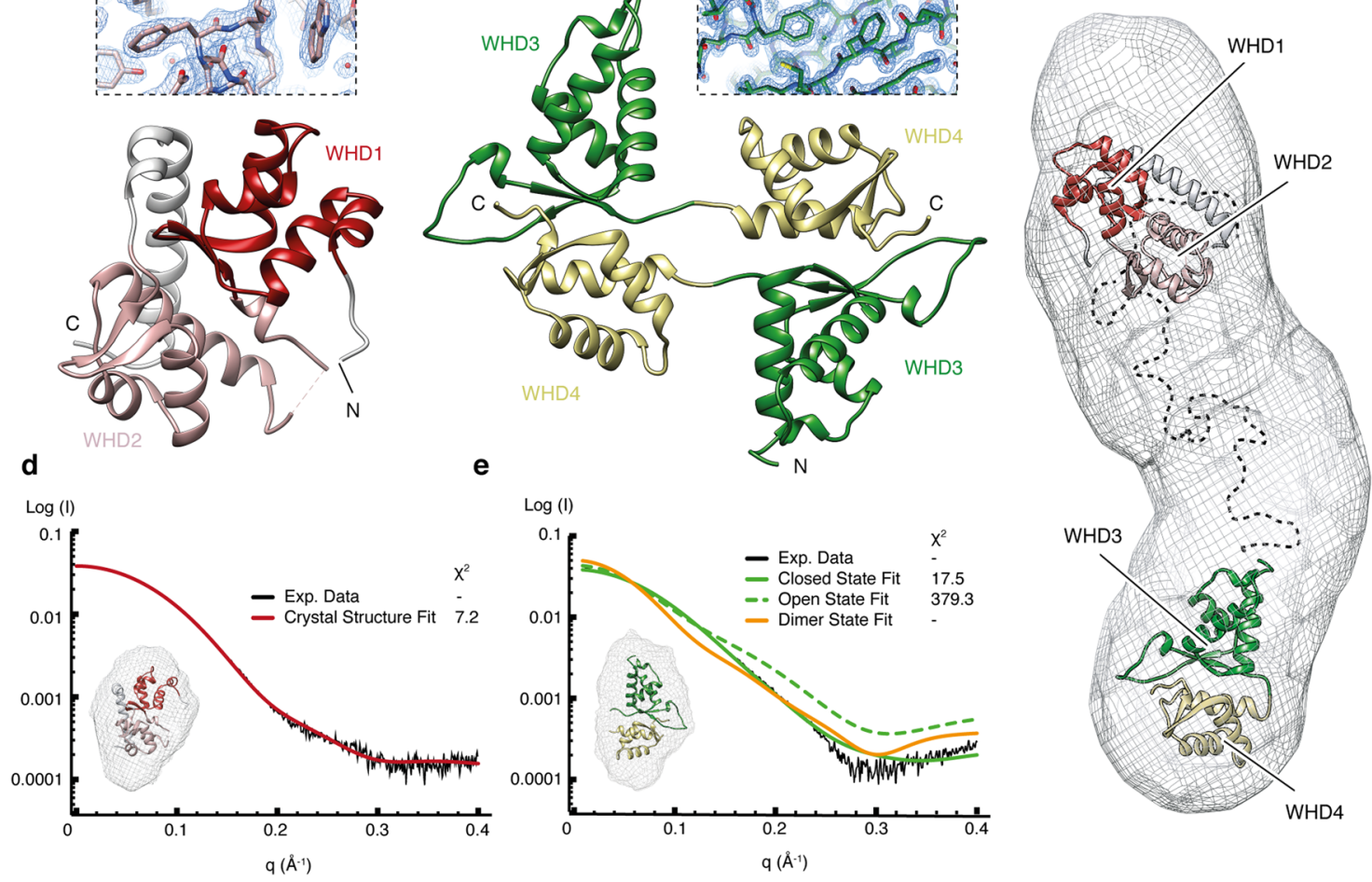

Fig. 3 Structure of the RPC5 subunit C-terminal region. a Domain architecture of RPC5 C terminus. tWHD1 and tWHD2 are coloured in red and green shades, respectively. Regions are depicted according to their presence (black line) or absence (black dashed line) in the crystal structures. DM refers to RPC5 dimerization module. b Crystallographic model of RPC5-WHD1 (dark red), RPC5-WHD2 (light red) and the linker regions (grey) in ribbon cartoon. Inset shows detail of the electron density map. c Overall structure of RPC5-tWHD2 crystallographic packing in ribbon cartoon. RPC5-WHD3 and RPC5WHD4 are shown in dark and light green, respectively, and the inset shows detail of the electron density map. d Fitting of RPC5-tWHD1 (red, inset) into the SAXS experimental data (black). e Fitting of RPC5-tWHD2 in 'closed' (green, inset), 'open' (dashed green) and dimer (orange) conformations into the SAXS experimental data (black). f Docking of RPC5-tWHD1 (red) and RPC5-tWHD2 (green) into the ab initio SAXS envelope generated from RPC5EXT SAXS data collection.

observed in the human RPC1 sequence in both the jaw and foot domains. The deletion in the jaw domain removed a small unstructured loop (Supplementary Fig. 5), whereas two deletions in the human RPC1 foot domain result in a rearranged, more compact foot structure (Supplementary Fig. 5). Interestingly, similar structural rearrangements have been observed in the mammalian Pol II foot domain, a region that provides a binding interface for auxiliary regulators such as the DSIF and the PAF complex ${ }^{20,21}$

In human RPC4, a small deletion removed a helix (residues 269-285), which in the yeast RPC4 protrudes back towards the Pol core and contacts RPC2 (Supplementary Fig. 5). Deletion of this region may therefore highlight a weaker association between the human RPC4/5 heterodimer and core when compared to the yeast enzyme. In the RPC5 dimerization module, structural alignment detected the insertion of a small loop in humans in addition to the large C-terminal insertion (RPC5EXT), which together suggest a slightly rearranged heterodimer module in human Pol III (Supplementary Fig. 5). Furthermore, comparison of the yeast and human stalk subunit RPC9 identified two additional deletions in the human structure which remove unstructured loops (not present in the cryoEM map of the corresponding yeast subunit). This comparative analysis of the Pol peripheral subcomplexes was limited in the human structure due to the flexibility of the RPC5EXT and heterotrimerclamp module. As a result, both the reported RPC3 iron-sulphur cluster $^{22}$ and the RPC5EXT, elements absent in the Saccharomyces cerevisiae Pol III structures ${ }^{3,4,23}$, were not visible in our EM map.

Structure of the RPC5 C-terminal extension. To gain insight into the structure and function of RPC5EXT, we determined the structure of its individual domains by X-ray crystallography (Supplementary Fig. 6, Fig. 3, and Tables 2 and 3). The RPC5EXT is formed by two consecutive tandem winged helix domains (tWHD1 residues 259-440; tWHD2 residues 556-708) connected by a 115 residue-long flexible linker. Such an architecture has not been reported for other components of the eukaryotic transcription apparatus and appears to be found exclusively in metazoan RPC5. Of the two tWHDs, tWHD1 is the most conserved while tWHD2 is absent in Caenorhabditis elegans and Drosophila melanogaster (Supplementary Fig. 7). The tWHD1 is formed by two juxtaposed winged helix domains that form a compact globular domain with one of the two recognition helices, typically involved in DNA binding, buried within the structure (Fig. $3 \mathrm{~b}$ ). The compact conformation of tWHD1 is observed also in solution as highlighted by small-angle X-ray scattering (SAXS) data (Fig. 3d and Supplementary Fig. 6). The tWHD2 structure revealed a dimer formed by 
Table 2 RPC5-tWHD1 (aa. 259-440) data collection, phasing and refinement statistics for MAD (SeMet) structures.

\begin{tabular}{|c|c|c|c|c|}
\hline & \multicolumn{2}{|l|}{ Crystal 1 (Native) } & \multicolumn{2}{|l|}{ Crystal 2 (SeMet) } \\
\hline \multicolumn{5}{|l|}{ Data collection } \\
\hline Space group & $P 6,22$ & $\mathrm{P} 6,22$ & $P 6,22$ & $P 6,22$ \\
\hline \multicolumn{5}{|l|}{ Cell dimensions } \\
\hline$a, b, c(\AA)$ & $56.30,56.30,275.88$ & $56.43,56.43,277.27$ & $56.44,56.44,277.17$ & $56.41,56.41,276.95$ \\
\hline \multirow{2}{*}{$\alpha, \beta, \gamma\left(^{\circ}\right)$} & $90,90,120$ & $90,90,120$ & $90,90,120$ & $90,90,120$ \\
\hline & & Peak & Inflection & Remote \\
\hline Wavelength & 0.91983 & 0.97965 & 0.97980 & 0.971970 \\
\hline Resolution $(\AA)$ & $48.01-2.23(2.29-2.23)$ & $48.87-2.72(2.79-2.72)$ & $48.88-2.63(2.70-2.63)$ & $48.11-2.50(2.56-2.50)$ \\
\hline$R_{\text {sym }}$ or $R_{\text {merge }}$ & $0.05(0.749)$ & $0.324(2.163)$ & $0.268(1.820)$ & $0.246(1.656)$ \\
\hline$|/ \sigma|$ & $26.9(5.7)$ & $8.7(1.5)$ & $9.4(1.5)$ & $8.7(1.2)$ \\
\hline Completeness (\%) & $100.0(100.0)$ & $100.0(100.0)$ & $100.0(100.0)$ & $100.0(100.0)$ \\
\hline Redundancy & $27.4(28.8)$ & $21.6(19.6)$ & $21.2(15.8)$ & $20.0(10.6)$ \\
\hline \multicolumn{5}{|l|}{ Refinement } \\
\hline Resolution $(\AA)$ & $45.97-2.23(2.31-2.23)$ & & & \\
\hline No. reflections & 376,023 & & & \\
\hline$R_{\text {work }} / R_{\text {free }}$ & $0.1800 / 0.2193$ & & & \\
\hline No. of atoms & 1496 & & & \\
\hline Protein & 1371 & & & \\
\hline Ligand/ion & 4 & & & \\
\hline Water & 121 & & & \\
\hline \multicolumn{5}{|l|}{$B$-factors } \\
\hline Protein & 50.52 & & & \\
\hline Ligand/ion & 89.50 & & & \\
\hline Water & 54.85 & & & \\
\hline \multicolumn{5}{|l|}{ R.m.s deviations } \\
\hline Bond lengths $(\AA)$ & 0.008 & & & \\
\hline Bond angles $\left({ }^{\circ}\right)$ & 0.84 & & & \\
\hline
\end{tabular}

Table 3 Rpc5-tWHD2 (aa. 556-708) data collection, phasing and refinement statistics for MAD (SeMet) structures.

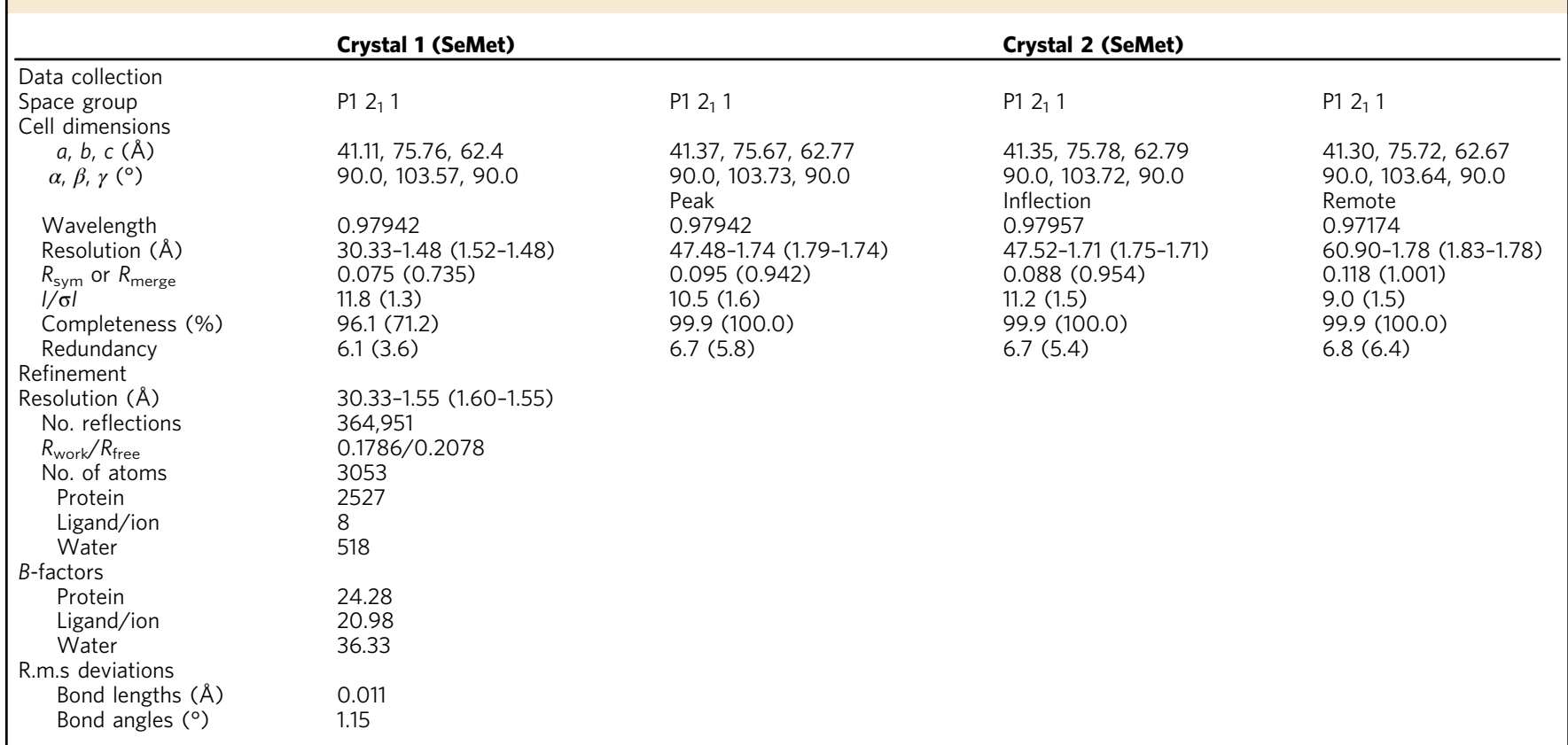

domain swapping (Fig. 3c). This arrangement is likely caused by the crystallization conditions and, in agreement with this hypothesis, SAXS data showed a monomeric conformation as the most likely in solution (Fig. 3e and Supplementary Fig. 6). Nevertheless, the two possible conformations of tWHD2, compact or elongated, suggests a degree of flexibility within this domain. Finally, SAXS analysis of a construct encompassing the full-length RPC5EXT support the model of two globular compact tWHD domains connected by a long flexible linker, spanning approximately up to $175 \AA$ in length (Fig. 3f and Supplementary Figs. 8 and 9).

Comparison with existing protein structures using the Dali server (http://ekhidna.biocenter.helsinki.fi/dali_server/) suggested similarities between tWHD1 and the WHD of S. cerevisiae Pol II general transcription factor TFIIF Rap30 subunit ${ }^{24-26}$ and with the tWHD of Pol I A49 subunit ${ }^{27-31}$. Both subunits are orthologs of RPC5 and involved in stabilization of the pre-initiation complexes (PICs), suggesting a putative functional link. However, although the position of TFIIF Rap30 WHD in the Pol II PIC clashes with the Bdp1 subunit of transcription factor TFIIIB in the Pol III PIC 3,4 (Fig. 4), the equivalent position of A49 tWHD in the Pol I PIC ${ }^{27}$ is accessible in the Pol III PIC (Fig. 4). Thus, one possibility is that, analogously to A49 tWHD, the RPC5-tWHD1 participates in an interaction with the upstream DNA and bound transcription factors, thus stabilizing the human Pol III PIC. In 
a

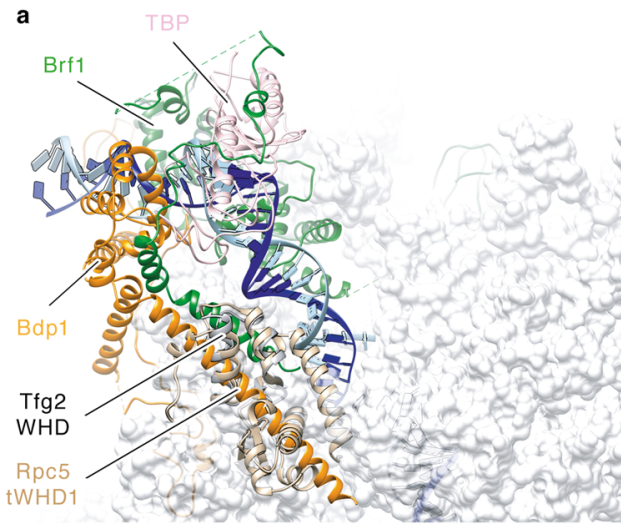

b

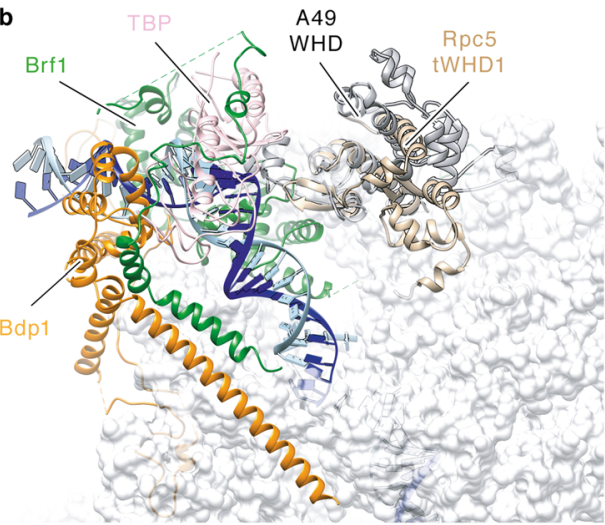

Fig. 4 Structural alignment of RPC5-tWHD1 to Pol I and Pol III PICs. a Structural alignment between S. cerevisiae RNA Pol II (PDB code: 5FYW) and RNA Pol III (PDB code: 6EU0). RPC5-tWHD1 (wheat) superimposition to yeast Tfg2 WHD (grey) leads to clashes with Bdp1 subunit stem motif (orange). b Structural alignment between S. cerevisiae RNA Pol I (PDB code: 5W66) and RNA Pol III (PDB code: 6EU0). RPC5-tWHD1 (wheat) superimposition to yeast A49 tWHD (grey) does not cause clashes with TFIIIB subunits Brf1 (green), TBP (pink) or Bdp1 (orange).

addition, the Dali server analysis retrieved similarities between the individual WHDs of RPC5EXT tWHD2 and the WHDs of cullin and cullin-like proteins, which are involved in ubiquitindependent proteolysis ${ }^{32}$.

The RPC5 extension is required for RNA Pol III stability. To gain insight into the functional role of RPC5EXT, we used small interfering RNA (siRNA) to knock down RPC5 in HEK293T cells and rescued it with ectopic expression of haemagglutinin (HA)tagged RPC5 constructs encompassing the full-length protein (RPC5FL) or a version of RPC5 devoid of either tWHD2 (RPC5 $\Delta$ tWHD2) or the entire RPC5EXT (RPC5 $\Delta$ C) (Supplementary Fig. 10a, b). Immunoprecipitation using anti-HA magnetic beads revealed that both RPC5FL, RPC5 $\Delta$ tWHD2 and $\mathrm{RPC} 5 \Delta \mathrm{C}$ are able to integrate into and pull down a bona fide intact Pol III complex, as probed by RPC1, RPC2 and RPC4 antibodies (Supplementary Fig. 10c). However, the corresponding immunoblots of whole-cell extracts, prior to the immunoprecipitation, indicate lower steady-state levels of RPC $5 \Delta \mathrm{C}$ compared to RPC5FL, pointing towards a direct role of RPC5EXT in enhancing RPC5 stability. To further explore the role of RPC5EXT in regulating RPC5 stability in the context of an intact Pol III complex, we employed a cycloheximide chase assay (Fig. 5). Levels of RPC5FL remained stable for the course of the experiment $(8 \mathrm{~h})$, as well as subunits RPC1 and RPC2, suggesting a relatively long half-life of the Pol III complex (Fig. 5a). On the contrary, RPC5 $\Delta$ tWHD2 and RPC5 $\Delta \mathrm{C}$ were rapidly degraded with RPC5 $\Delta \mathrm{C}$ almost completely depleted after only $2 \mathrm{~h}$ following cycloheximide treatment (Fig. 5b, c). Surprisingly, subunits RPC2 and, to a minor extent, RPC1 and RPC4 were also rapidly depleted, suggesting that RPC5EXT is essential for the stability of the whole Pol III complex.

Pathological genetic mutations map to Pol III subunit interfaces. Many studies have reported mutations of the Pol III enzyme that are related to human diseases, in particular heritable diseases, which affect the correct development of the CNS. Specifically, allele variants encoding mutated versions of the Pol III subunits RPC1, RPC2, RPAC1 and RPAC2 subunits have been established as causative mutations of hypomyelinating leukodystrophy $(\mathrm{HL})^{7-10,33-37}$, Treacher-Collins syndrome (TCS $)^{11,12}$ and Wiedemann-Rautenstrauch syndrome (WRS) ${ }^{13,14}$.

To rationalize these findings, we mapped known Pol III mutations on our high-resolution structure (Fig. 6 and
Supplementary Data 1). Reported mutations affecting CNS development tend to cluster in specific hotspots, very often at the interface of several Pol III subunits. For example, TCS mutations L51R and T50I in RPAC2 result in disruption of hydrophobic and salt-bridge interactions, respectively, at the interface with the RPAC1 subunit, suggesting a strong destabilizing effect that might impair correct assembly of the enzyme (Fig. 6). Analogously, most reported HL mutations lay at the interface of several subunits and have disruptive effects on these interfaces (Fig. 6 and Supplementary Data 1). Interestingly, WRS mutation R1069Q in subunit RPC1 disrupts a charged interaction with residue N1249 in the same subunit. This residue is itself mutated in $\mathrm{HL}$, possibly altering the interface between subunits RPC1 and RPABC1 in both pathologies. Overall, these finding indicate a general molecular mechanism from mutations resulting in CNS disorders, which is the partial loss of function of Pol III activity through destablization of the enzyme core.

Recently, Pol III mutations have also been described in patients affected by acute severe response to Varicella zoster virus (VZV) infection $15,16,38$. Most of these mutations map at the periphery of the Pol III enzyme and result in neutralizing basic charged residues exposed to the solvent in proximity of DNA-binding regions (Fig. 6). As human Pol III has been shown to display cytosolic DNA-sensing activity, it is conceivable that VZV mutations indeed impair proper DNA binding and transcription factor-independent RNA synthesis in the cytoplasm.

Overall, these findings are in agreement with previous work using the homologous yeast Pol III, and/or Pol I and Pol II enzymes to map disease-causing mutations ${ }^{8-10,15,39}$. However, the availability of a high-resolution structure of human Pol III enable the comprehensive mapping and rationalization of these allele variants with high confidence.

\section{Discussion}

Here we describe the $4.0 \AA$ resolution cryo-EM structure of apo human Pol III. The structure confirms the overall high-degree of structural homology with its $S$. cerevisiae counterpart but also highlights specific differences, such as a rearranged foot domain (Supplementary Fig. 5). Integrating cryo-EM data with X-ray crystallographic and SAXS data for the metazoan-specific RPC5EXT, detailed structural information has been obtained for the whole Pol III complex (Supplementary Fig. 11). Surprisingly, experiments in living cells highlighted a prominent role of RPC5EXT for the integrity of the Pol III complex. Absent in lower eukaryotes, RPC5EXT thus represents an additional 
a

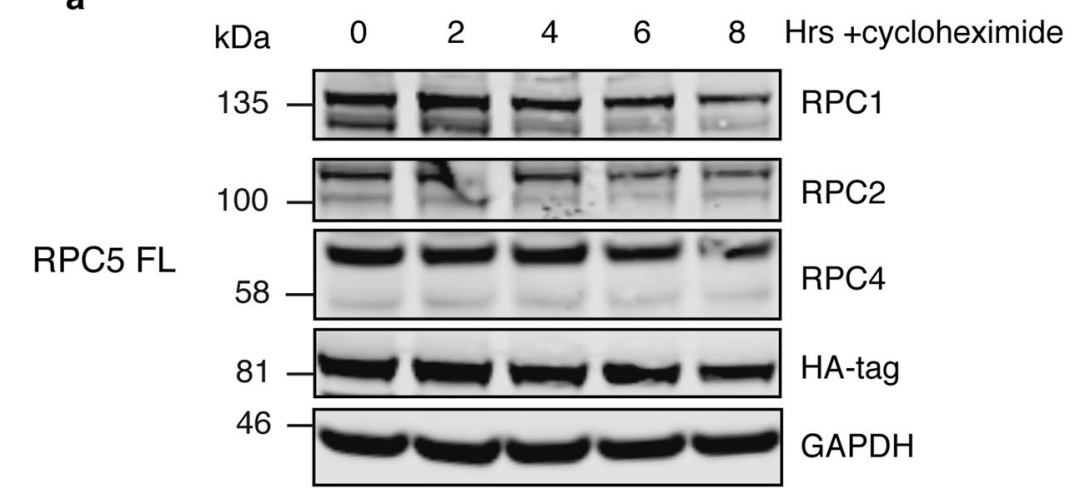

b

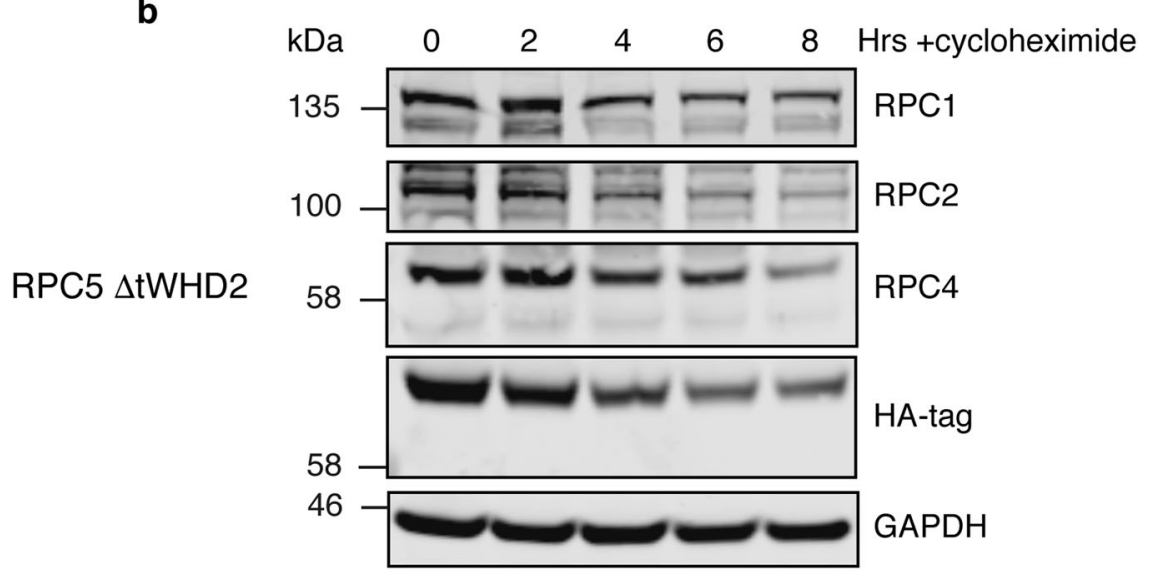

C

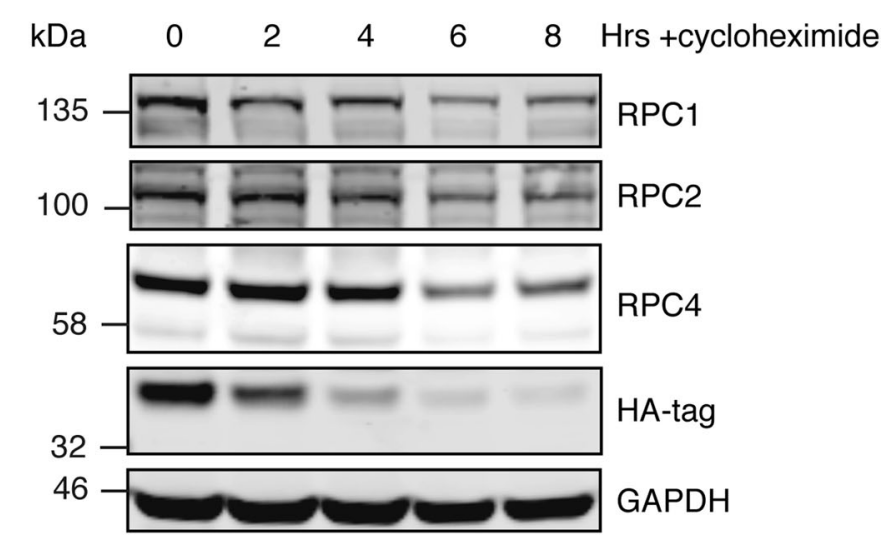

Fig. 5 Cycloheximide chase assay investigation of RPC5 protein stability. HEK293T cells were seeded, endogenous RPC5 was knocked down via siRNA and either the FL $\mathbf{a}, \Delta \mathrm{tWHD} 2 \mathbf{b}$, or $\Delta \mathrm{C} \mathbf{c}$, RPC5 constructs were transfected. After $24 \mathrm{~h}$, cycloheximide was added in at a concentration of $300 \mu \mathrm{g} / \mathrm{ml}$ and cells lysed at the specified time points. RPC1, 2, 4 and 5 (as shown via HA-tag antibody) levels were probed by western blotting. Displayed images are representative of three independent experiments. Source data are provided as a Source Data file.

metazoan-specific module, impacting on the correct assembly of Pol III. Several abundant phosphorylation sites have been identified in RPC5EXT, which, together with the evidence of structural similarities between RPC5EXT tWHD2 and factors involved in targeted degradation, suggests the intriguing hypothesis of an RPC5EXT-mediated layer of regulation impacting overall Pol III abundance in response to environmental cues that may have evolved in higher organisms.

Furthermore, the high-resolution structure of human Pol III enabled the mapping of more than $85 \%$ of reported Pol III genetic mutations with high precision, rationalizing their effects at a molecular level (Supplementary Data 1). Mutations affecting the CNS development tend to spatially cluster together and it seems likely that the severity of the phenotypes observed in HL, TCS and WRS correlate with the disruptive effect of such variants. For example, TCS mutations appear to be particularly disruptive at the interface of RPAC1 and RPAC2, two subunits shared between Pol I and Pol III. Interestingly, mutations N32I and N74S in RPAC1 mutations associated with HL lead to reduced Pol III assembly and nuclear import, without affecting Pol I ${ }^{7}$. This is consistent with our model, as these residues mediate interactions with Pol III-specific RPC1 and RPC2, respectively (Supplementary Data 1).

Finally, as Pol III represents a central nexus involved in the regulation of organismal growth, development and lifespan in eukaryotes and is often deregulated in cancer, the structure of the 


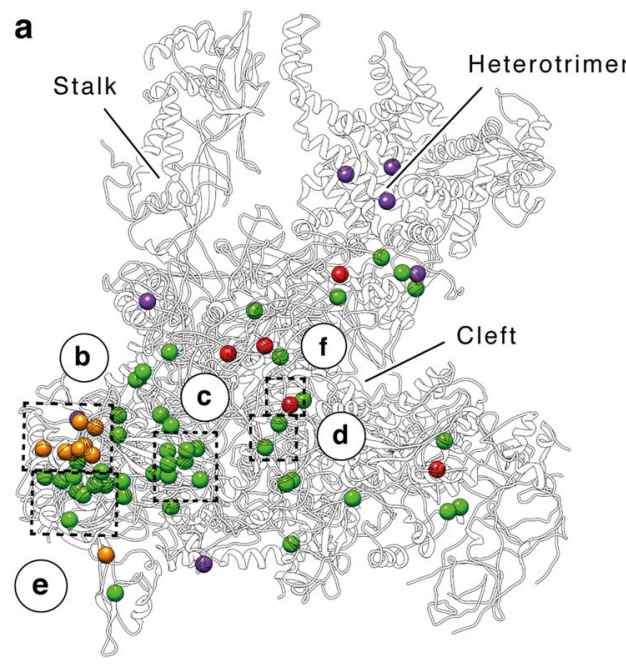

- Hypomyelinating Leukodystrophy

- Treacher Collins Syndrome

- VZV Susceptibility

- Wiedemann-Rautenstrauch Syndrome


Fig. 6 Mapping genetic mutations in human RNA Polymerase III. a The position of residues mutated in hypomyelinating leukodystrophy (HL, green), Treacher-Collins syndrome (TCS, orange), Wiedemann-Rautenstrauch syndrome (WRS, red) and VZV susceptibility (VZV, purple) is shown as solid spheres. b-f The close-up panels show details of the interfaces involved in TCS (b), HL (c-e) and WRS mutations (f). Side chains are shown in stick representation and Pol III subunits are coloured as in Fig. 2.

human enzyme will represent an invaluable tool to aid the design of small molecules capable of specifically targeting Pol III transcription for therapeutic purposes.

\section{Methods}

CRISPR/Cas9 genome editing. HeLa cells were cultured in Dulbecco's modified Eagle medium (DMEM, D6429, Sigma Aldrich) supplemented with $10 \%$ fetal bovine serum (FBS) (P40-37500, PAN-Biotech) and 1\% AAS (A5955, Sigma Aldrich). Genomic integration of Superfolder GFP (sfGFP) ORF at the C terminus of POLR1C was done by CRISPR/Cas9 based on a published protocol (Ran et al. ${ }^{40}$ ) performed as following.

Design of the guide RNAs (gRNAs) was done with a web-based tool (http:ICRISPR mit.edu) and annealed oligos (gRNAl $=5^{\prime}$-gCTAGTTCATCCAAGAAG

CGC-3'; gRNA2 $=5^{\prime}$-gCGGTTCAGATGGACTGAGCT- $3^{\prime}$ ) were cloned via BplI into the bicistronic Cas9n expression vector pSpCas9n(BB)-2A-Puro (PX462) V2.0, which 
was a gift from Feng Zhang (Addgene plasmid \#62987: https://n2t.net/addgene:62987; RRID: Addgene_62987). A donor plasmid carried a short GS-linker sequence with an embedded Human Rhinovirus (HRV) 3C protease cleavage site and the sfGFP ORF surrounded by two large sequence segments homologous to the insertion locus in the genome.

HeLa cells were transfected with a 1:1:1 mix of gRNA1 and gRNA2 vectors together with the donor plasmid using PolyJet transfection reagent (SL100688, SignaGen Laboratories) according to the manufacturer's instructions. Several days later, the GFP-expressing cells were enriched by flow cytometry using a Bio-Rad S3e cell sorter. GFP-positive cells were seeded on large culture dishes such that they could grow as single cell colonies. After 2-3 weeks, colonies were transferred manually into multi-well slides for live-cell imaging and were screened under identical microscope settings. The brightest clones were selected for expansion. These monoclonal populations were validated by PCR on extracted genomic DNA (using the Blood \& Tissue Kit, Qiagen).

The selected cell line was cultivated adherently and adapted to suspension growth as follows: Cells from 8 flasks (about $70 \times 10^{6}$ cells total; 83.3912.302, Sarstedt) were detached by incubation with trypsin $\left(25,300\right.$, Gibco) at $37^{\circ} \mathrm{C}$ for 5 $\mathrm{min}$, transferred to a spinner flask $(250 \mathrm{~mL}$ total volume; 4500 , Corning) and cultured in suspension with high-glucose DMEM (11965, Gibco) supplemented with $1 \%$ FBS (10,270, Gibco) and 1\% Penicillin/Streptomycin (P0781, Sigma Aldrich) under moderate stirring at $37^{\circ} \mathrm{C}, 5 \% \mathrm{CO}_{2}$ atmosphere. To expand the culture, $1 \times$ the current volume of fresh media including all supplements was added when cells reached a density of $\sim 3.5 \times 10^{5}$ cells $/ \mathrm{mL}$ and transferred to spinner flasks of increasing volume when required. Cells were collected by centrifugation and washed with phosphate-buffered saline (PBS) before flash-freezing the pellet.

For fluorescence imaging, cells were grown adherently on cover slips to $50 \%$ confluency. After washing the cells with pre-warmed $\left(37^{\circ} \mathrm{C}\right) \mathrm{PBS}$, they were fixed with $3.7 \%$ paraformaldehyde in PBS for $10 \mathrm{~min}$ at $37^{\circ} \mathrm{C}$. The fixation was stopped by addition of $100 \mathrm{mM}$ glycine in PBS for $5 \mathrm{~min}$ at $37^{\circ} \mathrm{C}$ and cells were washed twice with PBS. The cells on the cover slips were mounted on the specimen slide with the help of a drop Prolong Gold Antifade Mountant with 4',6-diamidino-2phenylindole (DAPI) (P36941, Thermo Fisher Scientific) and dried for at least 3 days in the dark.

The fluorescent specimens were imaged using a Zeiss Axio Observer.Z1/7 microscope and a $\times 63$ oil-objective lens. DAPI staining was detected with the help of a $405 \mathrm{~nm}$ excitation laser and for the emission a wide band-pass filter (300-720 $\mathrm{nm}$ ) was used. For sfGFP detection, a $488 \mathrm{~nm}$ laser and the same band-pass filter $(300-720 \mathrm{~nm})$ was applied. The images were captured with the Airyscan mode and detector. Processing was done using the Zeiss AxioVision software, the Zeiss ZEN 3.0 (ZEN lite) software and Fiji.

The selected homozygous cell line was further characterized by western blotting. Cells from a confluent $6 \mathrm{~cm}$ plate (about $2.7 \times 10^{6}$ cells, 83.3901 .300 , Sarstedt) were collected with $300 \mu \mathrm{l}$ of boiling $1 \times$ SDS loading dye (3\% (w/v) glycerol, $1.68 \%(\mathrm{v} / \mathrm{v})$ $\beta$-mercaptoethanol, $0.03 \%$ (w/v) bromophenol blue, $26 \mathrm{mM}$ Tris $\mathrm{pH} 6.8,0.42 \%$ (w/v) SDS) and rigorously shaken at $95^{\circ} \mathrm{C}$ for $15 \mathrm{~min}$. Prestained Marker $(7719 \mathrm{~S}$, NEB) and $10 \mu$ of sample from the parental and the newly generated cell line were loaded on a SDS gel (NP0223BOX, Thermo Fisher Scientific) and proteins separated by electrophoresis. After blotting (Trans-Turbo Blot, Bio-Rad) on a membrane $(1,704,275$, Bio-Rad), Ponceau S staining confirmed equal loading. The tagged protein RPAC1 was detected by the primary antibody (sc-374443, Santa Cruz Biotechnology), which was subsequently detected by the fluorescently labelled secondary antibody (926-32210, Li-COR). Prestained Marker and secondary antibody were detected at different wavelengths (Odyssey Infrared Imager Model 9120, Li-COR).

\section{Anti-GFP pulldown from nuclear and cytosolic fractions. A total of $\sim 7 \mathrm{~L}$} POLR1C-GFP Hela cells were grown in a spinner flask (Corning) and collected by centrifugation, yielding a cell pellet of $8.1 \mathrm{~g}$ (estimated total of $2.3 \times 10^{9}$ cells) Nuclear extract production was based on a published protocol ${ }^{41}$. The cell pellet was resuspended in $9.8 \mathrm{ml}$ of MC Buffer (10 mM HEPES-KOH pH 7.6, $10 \mathrm{mM}$ KOAc, $0.5 \mathrm{mM} \mathrm{Mg}(\mathrm{OAc})_{2}, 5 \mathrm{mM}$ dithiothreitol (DTT), $0.5 \mathrm{mM}$ phenylmethylsulfonyl fluoride (PMSF)) and incubated for 5 min on ice. Following dounce homogenization, nuclei and cytosolic fractions were separated by centrifugation using a Sorvall SS34 rotor at $18,000 \times g$ at $4{ }^{\circ} \mathrm{C}$ for $5 \mathrm{~min}$. This resulted in a nuclear pellet of $5.1 \mathrm{~g}$, which was resuspended with $6.7 \mathrm{ml}$ 'Roeder C Buffer' (25\% v/v glycerol, 20 mM HEPES-KPOH pH 7.9, $1.5 \mathrm{mM} \mathrm{MgCl} 2,0.2 \mathrm{mM}$ EDTA pH $8.0,420 \mathrm{mM} \mathrm{NaCl}$, $0.5 \mathrm{mM}$ DTT, $0.5 \mathrm{mM}$ PMSF) and corresponds to $12 \mathrm{ml}$ of nuclear extract. Nuclei were lysed with a dounce homogenizer, slowly stirred at $4^{\circ} \mathrm{C}$ and centrifuged in a Sorvall SS34 rotor at $16,000 \times g$ at $4^{\circ} \mathrm{C}$ for $30 \mathrm{~min}$. Nuclear extracts and cytosolic fraction were split into fractions of $0.5 \mathrm{~mL}$ each.

An aliquot of nuclear extract and cytosolic fraction were each supplemented with $500 \mu \mathrm{L}$ wash buffer (5\% v/v glycerol, $20 \mathrm{mM}$ HEPES 7.8, $420 \mathrm{mM} \mathrm{NaCl}, 1 \mathrm{mM}$ $\mathrm{MgCl}_{2}, 0.1 \mathrm{mM} \mathrm{ZnCl}, 2 \mathrm{mM} \beta$-mercaptoethanol, $0.5 \mathrm{mM}$ PMSF) and 5 units DNase I (Thermo Fished Scientific) followed by $30 \mathrm{~min}$ incubation at $4{ }^{\circ} \mathrm{C}$ in an overhead mixer. Debris was removed by centrifugation (Eppendorf Centrifuge 5427 R, Rotor FA-45-12-17) 13k r.p.m., $4^{\circ} \mathrm{C}, 30$ min. Nuclear extracts and cytosolic fraction were each bound to $20 \mu \mathrm{L}$ (slurry) 'GFP selector' Beads (NanoTag) for $2 \mathrm{~h}$ and washed twice with $0.5 \mathrm{~mL}$ wash buffer times and washed/eluted as described above. Elution was carried out with $3 \mathrm{C}$ protease in $50 \mu \mathrm{L}$ wash buffer at $4{ }^{\circ} \mathrm{C}$ for $2 \mathrm{~h}$.
Pre-cast SDS-polyacrylamide gel electrophoresis (PAGE) gels (4-12\% NuPAGE Bis-Tris, Thermo Scientific) were loaded with $12.5 \mu \mathrm{L}$ fractions.

Large-scale human RNA Pol purification. Large-scale cell growth was carried out at the Cell Services Scientific Technical Platform at The Francis Crick Institute, London. Adherent HeLa POLR1C-GFP cells were grown in DMEM-4 medium supplemented with $1 \%$ fetal bovine serum (FCS), $1 \%$ Glutamax and $1 \%$ Penicillin/ Streptomycin. Confluent cells were collected by trypsin treatment followed by gentle centrifugation. The cell pellet was subsequently resuspended in RPMI-1640 supplemented with $5 \%$ FCS, $1 \%$ Glutamax and $1 \%$ penicillin/streptomycin, to allow for cell growth in suspension. Cells were expanded in suspension using a small glass spinner flask flushed with $\mathrm{CO}_{2}$ at $37^{\circ} \mathrm{C}$. Cells were expanded to a maximum volume of $1.2 \mathrm{~L}$ per growth in a $3 \mathrm{~L}$ glass spinner flask. Cells were grown to a density of to $1 \times 10^{6}$ cells $/ \mathrm{ml}$ with viability maintained at $>90 \%$. Following growth, cells were collected by gentle centrifugation at room temperature. The resulting cell pellets were washed with PBS and cells pelleted again via centrifugation. The final cell pellets were stored at $-80^{\circ} \mathrm{C}$ prior to purification.

For large-scale purification of human RNA Pol, whole-cell lysate was produced from a cell pellet derived from $20 \mathrm{~L}$ of HeLa cells grown to $1 \times 10^{6}$ cells $/ \mathrm{ml}$ density. The cell pellet was resuspended in lysis buffer $(50 \mathrm{mM}$ Tris- $\mathrm{HCl} \mathrm{pH} 8.0,250 \mathrm{mM}$ $\left(\mathrm{NH}_{4}\right)_{2} \mathrm{SO}_{4}, 20 \%$ v/v glycerol, $1 \mathrm{mM} \mathrm{MgCl}, 10 \mu \mathrm{M} \mathrm{ZnCl}_{2}, 10 \mathrm{mM} \beta$ mercaptoethanol) and two protease-inhibitor tablets (Roche) added. Lysis was performed through repeated passage of the cell suspension through a dounce followed by sonication with the resulting lysate cleared through centrifugation at $28,000 \times g$ at $4{ }^{\circ} \mathrm{C}$ for $40 \mathrm{~min}$ followed by filtration of the soluble fraction through gauze. The cleared lysate was incubated with $1 \mathrm{ml}$ of GFP selector beads $50 \%$ slurry (Nanotag) pre-equilibrated in lysis buffer. Beads were incubated for $3 \mathrm{~h}$ at $4{ }^{\circ} \mathrm{C}$ under continuous rotation. Beads were washed with $60 \times$ slurry volume in lysis buffer and eluted through overnight incubation at $4^{\circ} \mathrm{C}$ with $160 \mu$ of HRV $-3 \mathrm{C}$ protease (Millipore) in a final volume of $2-3 \mathrm{ml}$. Following elution, the eluate was collected through gentle centrifugation of the beads at $1000 \times g$ and collection of the supernatant. The beads were then washed in double the eluate volume with wash buffer $\left(50 \mathrm{mM}\right.$ Tris- $\mathrm{HCl} \mathrm{pH} 8.0,50 \mathrm{mM}\left(\mathrm{NH}_{4}\right)_{2} \mathrm{SO}_{4}, 1 \mathrm{mM} \mathrm{MgCl}, 10 \mu \mathrm{M}$ $\mathrm{ZnCl}_{2}, 10 \mathrm{mM} \beta$-mercaptoethanol) and the resulting wash fraction combined with the eluate to dilute the $\left(\mathrm{NH}_{4}\right)_{2} \mathrm{SO}_{4}$ to $\sim 120 \mathrm{mM}$. The eluate mixture was further diluted through addition of an equivalent volume of Tris buffer $(50 \mathrm{mM}$ Tris- $\mathrm{HCl}$, $1 \mathrm{mM} \mathrm{MgCl} 2,10 \mu \mathrm{M} \mathrm{ZnCl}_{2}, 10 \mathrm{mM} \beta$-mercaptoethanol) to reduce the final $\left(\mathrm{NH}_{4}\right)_{2} \mathrm{SO}_{4}$ concentration to $\sim 60 \mathrm{mM}$. Next, the eluate was loaded onto a MonoQ GL 5/50 column (GE Healthcare) and eluted in a linear gradient from $60 \mathrm{mM}$ to $1 \mathrm{M}\left(\mathrm{NH}_{4}\right)_{2} \mathrm{SO}_{4}$ in $50 \mathrm{mM}$ Tris- $\mathrm{HCl} \mathrm{pH} \mathrm{8.0,1} \mathrm{mM} \mathrm{MgCl}, 10 \mu \mathrm{M} \mathrm{ZnCl}_{2}, 10 \mathrm{mM} \beta$ mercaptoethanol. MonoQ purification produced two peaks corresponding to RNA Pol I (eluting at $\sim 380 \mathrm{mM}\left(\mathrm{NH}_{4}\right)_{2} \mathrm{SO}_{4}$ ) and RNA Pol III (eluting at $\sim 550 \mathrm{mM}$ $\left.\left(\mathrm{NH}_{4}\right)_{2} \mathrm{SO}_{4}\right)$. Human RNA Pol III fractions were collected and diluted to a final $\left(\mathrm{NH}_{4}\right)_{2} \mathrm{SO}_{4}$ concentration of $\sim 110 \mathrm{mM}$. The sample was then concentrated using a Vivapsin $500(100,000$ Molecular Weight Cut Off to a final concentration of $\sim 0.05-0.1 \mathrm{mg} / \mathrm{ml}$. The concentrated sample was used immediately for grid preparation.

RNA elongation and cleavage assay. Human Pol III $(0.5,1$ or 2 pmol) was preincubated with 0.25 pmol of pre-annealed minimal nucleic acid scaffold (template DNA: 5'-CGAGGTCGAGCGTTGTCCTGGT-3', non-template DNA: 5'-CG CTCGACCTCG-3'; RNA: 5'-FAM-AACGGAGACCAGGAC-3') in transcription buffer (20 mM Hepes pH 7.8, 42-168 mM $\left(\mathrm{NH}_{4}\right)_{2} \mathrm{SO}_{4}$ (hs Pol III buffer), $8 \mathrm{mM}$ $\mathrm{MgSO}_{4}, 10 \mu \mathrm{M} \mathrm{ZnCl}_{2}, 10 \%(\mathrm{v} / \mathrm{v})$ glycerol, $10 \mathrm{mM} \mathrm{DTT}$ ) for $1 \mathrm{~h}$ at $20^{\circ} \mathrm{C}$ in a $45 \mu$ reaction. For RNA elongation, $10 \mu \mathrm{mol}$ of each Nucleotide triphosphate was added and the reaction was incubated for $1 \mathrm{~h}$ at $28^{\circ} \mathrm{C}$. To examine cleavage activity, the preincubated reaction was incubated for $1 \mathrm{~h}$ at $28^{\circ} \mathrm{C}$ without the addition of NTPs. In the following, nucleic acid purification was examined by adding $5 \mathrm{M} \mathrm{NaCl}$ to an end concentration of $0.5 \mathrm{M}$ and $800 \mu \mathrm{l} 100 \%$ ethanol. After precipitation for at least $1 \mathrm{~h}$ at $-20^{\circ} \mathrm{C}$, the sample was centrifuged for $30 \mathrm{~min}$ at $20,000 \times \mathrm{g}$ and $4^{\circ} \mathrm{C}$. The pellet was washed with $80 \%$ ethanol and, after drying, resuspended in $1 \times$ RNA loading dye (4 M Urea, $1 \times$ Tris-Borate-Ethylenediaminetetraacetic acid, $0.01 \%$ bromophenol blue, $0.01 \%$ xylene cyanol). The sample was heated to $95^{\circ} \mathrm{C}$ for 5 min. As control, $0.25 \mathrm{pmol}$ of scaffold was treated identically, without addition of Pol and NTPs. FAM-labelled RNA product $(0.125 \mathrm{pmol})$ was separated by gel electrophoresis (20\% polyacrylamide gel containing $7 \mathrm{M}$ Urea) and visualized with a Typhoon FLA9500 (GE Healthcare).

\section{Cryo-EM sample preparation and data collection. Human Pol III cryo-EM} samples were prepared on C-Flat 1.2/1.3 (400 mesh) grids coated with a thin film of continuous carbon prepared in house. Grids were glow discharged at $15 \mathrm{~mA}$ for 30 s using a PELCO EasyGlow instrument prior to sample addition. A $3 \mu$ volume of sample at $\sim 0.06 \mathrm{mg} / \mathrm{ml}$ concentration was applied and incubated for $30 \mathrm{~s}$ at $18^{\circ} \mathrm{C}$ and $100 \%$ humidity. Grids were blotted for $1 \mathrm{~s}$ at blot force 1 with a $0.5 \mathrm{~s}$ drain time and plunge frozen in liquid ethane using the VitroBot Mark IV system (FEI).

Data collection was carried out using a FEI Titan Krios transmission electron microscope (Thermo Fisher) operating at $300 \mathrm{KeV}$ and equipped with a Falcon III direct electron detector (Astbury Biostructure Laboratory, University of Leeds). Separate data collections were carried out for both untilted and $30^{\circ}$ tilted data sets. 
All data sets were imaged using EPU automated acquisition software with the Falcon III operating in electron counting mode at a nominal magnification of $\times 75,000$ and a calibrated sampling of $1.065 \AA /$ pixel. For untilted data collection, 3115 movies were collected. Movies were collected over 45 frames with a $70 \mathrm{~s}$ exposure time and a total dose of $44.1 e^{-}$, giving a dose per frame of $0.98 e^{-} / \AA^{2}$ and a dose rate of $0.63 e^{-} / \AA^{2} / \mathrm{s}$. Data were collected over a defocus range of $-1 \mu \mathrm{m}$ to $-3 \mu \mathrm{m}$. Tilted data collection was carried out at $30^{\circ}$ in two separate sessions. The first session collected 921 movies, with a total dose of $37.8 e^{-}$fractionated over 38 frames during a $70 \mathrm{~s}$ exposure, yielding a dose per frame of $0.99 e^{-} / \AA^{2}$ and a dose rate of $0.54 e^{-} / \AA^{2} / \mathrm{s}$. The second session collected 1703 movies, imaged with a total dose of $40.6 e^{-}$fractionated over 38 frames during a $70 \mathrm{~s}$ exposure. This gave dose per frame of $1.07 e^{-} / \AA^{2}$ and a dose rate of $0.58 e^{-} / \AA^{2} /$ s. In both tilted data collections, micrographs were collected using a -1.2 to $-3 \mu \mathrm{m}$ defocus range.

Cryo-EM image processing. Frame alignment and dose weighting was carried out on-the-fly using MotionCor $2^{42}$. Following motion correction, CTFFIND4 implemented in the cisTEM software package was used for contrast transfer function (CTF) estimation ${ }^{43}$. Particle picking was carried out using the ab initio particle picking option in cisTEM ${ }^{44}$ and resulting particles exported to Relion $3.1^{45}$. Subsequent $2 \mathrm{D}$ and $3 \mathrm{D}$ classification, refinement and post-processing steps were carried out using Relion 3.1, and ab initio model generation using Cryosparc v2 ${ }^{46}$. For the untilted dataset, 332,238 particles were selected, yielding a final particle set of 139,891 particles corresponding to hPol III following multiple rounds of 2D classification. This particle subset was used to generate an initial model of the hPol III structure using the ab initio model functionality in Cryosparc v2. Similarly, 87,075 particles were selected from $262430^{\circ}$ tilted micrographs, yielding 32,787 particles following 2D classification. Both particle sets were combined generating the merged particle set of 172,678 particles. This was subject to 3D classification in Relion 3.1 using the Cryosparc ab inito model as a reference. Classification produced 5 classes, with a single class (class 4 , containing 68,291 particles) corresponding to the complete Pol molecule. This class was refined and subject to CTF refinement. This was a sequential procedure, first correcting for trefoil and fourthorder aberrations, followed by correction for magnification anisotropy in the second step. In the final step, the defocus was refined on a per particle basis to correct for errors in CTF estimation for tilted particles. Following this, a further refinement was carried out, yielding a model at $3.7 \AA$ resolution at the gold-standard 0.143 Fourier shell correlation (FSC) cut-off criterion. Following refinement and post processing, the map was filtered according to the local resolution of each region using the local resolution functionality implemented in Relion 3.1. Inspection of the resulting density revealed poor density and low resolution of the heterotrimer region. To improve this region, a local mask was generated and 3D classification carried out without alignment localized to the heterotrimer. This produced 3 classes, of which 1 (containing 25,369 particles) produced a model with improved heterotrimer density following consensus refinement. This was subject to further CTF refinement, consensus refinement and local resolution estimation to produce the final model reporting $4.0 \AA$ global resolution at the 0.143 FSC cut-off criterion.

Cryo-EM model building and refinement. As an initial step, homology models were generated for all core (RPC1, RPC2, RPC10, RPAC1, RPAC2, RPABC1, RPABC2, RPABC3, RPABC4 and RPABC5), heterodimer (RPC4 and RPC5) and stalk (RPC8 and RPC9) subunits using the PHYRE2 webserver ${ }^{47}$. These were rigidly fitted into the locally filtered map using the fitted yeast apo-RNA Pol III structure (RCSB Protein Data Bank (PDB) code: 6EU2) as a guide for the relative positioning of the subunits in UCSF Chimera ${ }^{48}$. The placed homology models were then fitted manually to the density using the COOT software package ${ }^{49}$, at this stage regions not present in the EM density were removed from the model. Following manual fitting, the model was fitted using the real-space refinement functionality in PHENIX ${ }^{50}$. The lower resolution of the more dynamic heterotrimer region did not permit the use of this strategy for these subunits. Therefore, the existing crystal structure of human RPC3 in complex with a fragment of RPC7 ${ }^{51}$ (RCSB PDB Code: $5 \mathrm{AFQ}$ ) was structurally aligned with the yeast heterotrimer in the yeast apo-RNA Pol III structure in UCSF Chimera. Comparison revealed a highly similar structure and relative arrangement for the RPC3 and RPC7 regions present in both structures. Further to this, a homology model for RPC6 was generated using PHYRE2. This was structurally aligned in UCSF Chimera to the yeast RPC6 subunit present in the yeast apo Pol III structure. The region of human RPC6 consisting of residues 174-289 was selected for inclusion in the model, as this was the region which corresponded to residues 171-271 of yeast RPC6, which were visible in the yeast RNA Pol III apo state ${ }^{4}$. Following selection of the relevant models, they were positioned using the yeast apo structure as a guide and then fitted to the human EM map using the sequential fit option in UCSF chimera.

RPC5 cloning, expression and purification. Based on secondary structure predictions using PsiPred ${ }^{52}$ and HHPred programmes ${ }^{53}$, we designed 13 different constructs of the C-terminal extension of RPC5 subunit (Uniprot ID Q9NVU0). A PCR-based strategy was used to amplify fragments of RPC5-tWHD1, RPC5tWHD2 and RPC5EXT from its genomic DNA (Genscript). The constructs were subsequently cloned into pOPINF or pOPINJ plasmids for bacterial expression or into pACEBacl plasmid for baculovirus-insect cells expression. Two hexahistidine- tagged constructs that rendered high yield expression of undegraded proteins (RPC5 (259-440) and RPC5 (556-708)) were selected for large-scale production. Both protein constructs were expressed and purified following the same protocol Cells were grown at $37^{\circ} \mathrm{C}, 200$ r.p.m. in Terrific Broth to $\mathrm{OD}_{600}=1.5$ and protein expression was induced with $1 \mathrm{mM}$ isopropyl $\beta$-D-1-thiogalactopyranoside at $20^{\circ} \mathrm{C}$ overnight. All subsequent steps were performed at $4{ }^{\circ} \mathrm{C}$. Collected cells were resuspended in $20 \mathrm{mM}$ HEPES pH 7.9, $150 \mathrm{mM} \mathrm{NaCl}, 10 \mathrm{mM}$ imidazole and $10 \mathrm{mM} \beta$-mercaptoethanol supplemented with DNAse I and two protease-inhibitor tablets (Roche). After a $30 \mathrm{~min}$ incubation, the sample was sonicated and fractionated by centrifugation at 20,000 r.p.m. for $40 \mathrm{~min}$. Then, the soluble fraction was loaded in a HisTrap HP $5 \mathrm{~mL}$ affinity column (GE Healthcare) pre-equilibrated with lysis buffer. After extensive washes of the chromatographic column, the protein was eluted with lysis buffer supplemented with $250 \mathrm{mM}$ imidazole. The sample was diluted to $70 \mathrm{mM} \mathrm{NaCl}$ and injected into an HiTrap Heparin HP $5 \mathrm{ml}$ (GE Healthcare) column equilibrated with $20 \mathrm{mM}$ HEPES pH 7.9, $70 \mathrm{mM} \mathrm{NaCl}$ and $10 \mathrm{mM} \beta$-mercaptoethanol. The protein was subsequently eluted using an isocratic gradient from $70 \mathrm{mM}$ to $2 \mathrm{M} \mathrm{NaCl}$ in 30 column volumes. Fractions containing RPC5 constructs were identified by SDS-PAGE analysis. Cleavage of the His-tag was performed overnight incubating the protein with $3 \mathrm{C}$ protease in a 1 : 50 molar ratio (3C protease: RPC5). Uncleaved His-tagged proteins were removed by incubation of the sample with $1 \mathrm{ml}$ HisPur ${ }^{\mathrm{TM}}$ (Thermo Fisher) nickel resin for $1 \mathrm{~h}$ at $4^{\circ} \mathrm{C}$. The cleaved protein was concentrated to $5 \mathrm{ml}$ and loaded in a HiLoad $16 / 600$ Superdex $75 \mathrm{pg}$ gel-filtration column (GE Healthcare) equilibrated with 50 $\mathrm{mM}$ Tris- $\mathrm{HCl} \mathrm{pH} \mathrm{7.5,} 150 \mathrm{mM} \mathrm{NaCl}$ and $10 \mathrm{mM} \beta$-mercaptoethanol. Purified RPC5 (259-440) and RPC5 (556-708) were concentrated to 30 and $80 \mathrm{mg} / \mathrm{ml}$, respectively, flash-frozen and stored at $-80^{\circ} \mathrm{C}$

The expression of selenomethionine-derivatized proteins was performed in the methionine-auxotroph Escherichia coli B834(DE3) strain (Novagen) using SelenoMet ${ }^{\mathrm{TM}}$ medium (Molecular Dimensions) supplemented with SelenoMet Nutrient Mix and $40 \mathrm{mg} / \mathrm{l} \mathrm{L}$-selenomethionine (SeMet). Purification of the proteins was performed as described for the native proteins.

The expression of the whole C-terminal extension of RPC5 (referred as RPC5EXT) was performed in the insect cells/baculovirus expression system. Largescale suspension cultures $(300 \mathrm{~mL})$ of High Five insect cells at $0.5 \times 10^{6}$ cells $/ \mathrm{ml}$ were grown in Insect-Xpress media (Lonza) and inoculated with P2 baculovirus solution containing the RPC5 constructs. Proliferation arrest was assessed by measurement of GFP production until fluorescence reached a plateau. Cells were collected at $800 \times g$ for $5 \mathrm{~min}$ and the pellets were stored at $-20^{\circ} \mathrm{C}$. After a milder sonication step, purification was performed following the protocol described above. Finally, protein was concentrated to $10 \mathrm{mg} / \mathrm{mL}$, flash-frozen in liquid nitrogen and stored at $-80^{\circ} \mathrm{C}$

Crystallization, data collection and structure determination. Crystals used for structure determination were grown from a 1:1 ratio solution (protein : reservoir) using the vapour diffusion technique at $4{ }^{\circ} \mathrm{C}$. RPC5 (259-440) crystals in $\mathrm{P}_{1} 22$ space group were obtained at $30 \mathrm{mg} / \mathrm{mL}$ after $3-4$ days equilibration in $3.2 \mathrm{M}$ $\mathrm{NaCl}, 100 \mathrm{mM}$ Sodium Acetate $\mathrm{pH} 4.6$ and $10 \mathrm{mM} \mathrm{ZnCl}_{2}$. SeMet-RPC5 (259-440) crystals in the same space group were obtained at similar conditions but required the use of streak seeding with diluted native crystals to favour nucleation. RPC5 (556-708) crystals in $\mathrm{P} 2$ space group grew at $35 \mathrm{mg} / \mathrm{mL}$ in $3.2-3.8 \mathrm{M}$ Ammonium Acetate and $100 \mathrm{mM}$ Bis-Tris Propane $\mathrm{pH}$ 6.5-7 after 2 weeks. Crystallization of SeMet-RPC5 (556-708) protein was performed under identical conditions. All crystals were flash-frozen in liquid nitrogen using perfluoropolyether oil (Hampton Research) as a cryoprotectant.

A dataset from native RPC5 (259-440) was collected at 0.9198 A wavelength in I24 beamline of Diamond Light Source (DLS). In addition, multi-wavelength anomalous dispersion (MAD) data collections were performed at the peak, remote and inflection wavelengths from SeMet-derivatized crystals of RPC5 (259-440) and RPC5 (556-708) in I03 beamline of DLS. Using the MAD dataset, an initial mode of SeMet-RPC5 (259-440) at $2.7 \AA$ was determined with the SHELXC/D/E suite from the HKL2Map programme (for phase determination) and the Buccaneer software (for model building). The native structure at $2.2 \AA$ was solved by molecular replacement using the initial SeMet model as a search reference in PHENIX.automr. Subsequent refinement was performed using COOT and PHENIX suites. The structure of RPC5 (556-708) at $1.48 \AA$ was solved from the SeMet data sets using HKL2Map and Buccaneer programmes, and further refined to acceptable $R_{\text {free }} / R_{\text {work }}$ values with COOT and PHENIX. Protein secondary structure assignment from the atomic coordinates was performed using STRIDE ${ }^{54}$.

RPC5 SAXS data collection and processing. SAXS data collection was carried out at the SWING small- and wide-angle scattering beamline, SOLEIL Synchrotron, Saint Aubin, France. Purified RPC5EXT $(164 \mu \mathrm{M})$, tWHD1 $(922 \mu \mathrm{M})$ and tWHD2 $(3691 \mu \mathrm{M})$ were passed through a Bio SEC-3 HPLC column (Agilent) at $0.2 \mathrm{ml} / \mathrm{min}$ in $50 \mathrm{mM}$ Tris- $\mathrm{HCl} \mathrm{pH} \mathrm{7.5,150} \mathrm{mM} \mathrm{NaCl}, 10 \mathrm{mM} \beta$-mercaptoethanol with protein elution monitored using $A_{280}$. Data were collected using an Eiger $\mathrm{X}$ $4 \mathrm{M}$ detector (Dectris) at a $2 \mathrm{~m}$ distance, using a $q$-range of $0<q<0.68 \AA^{-1}$. Data were reduced and buffer subtraction performed at the beamline. Data analysis was carried out using the ScÅtter software package for determination of radius of gyration $\left(R_{\mathrm{g}}\right), P(r)$ distribution, particle maximum dimension $\left(D_{\max }\right)$ parameters and for qualitative flexibility analysis (through generation of $R_{\mathrm{g}}$-Normalized 
Kratky, SIBLYS and Porod-Debeye plots ${ }^{55}$. Volumetric bead modelling was performed using the DAMMIN software package ${ }^{56}$. Briefly, ab inito bead models were calculated using DAMMIN ten times for each construct, fitting over the $q$-range of $0<q<0.25 \AA^{-1}$. The resulting bead models were averaged and filtered using the DAMAVER package ${ }^{57}$, generating the final bead model reconstruction.

Comparison of the theoretical scatter profiles of the determined crystal structures for the tWHD1 and tWHD2 constructs was performed using the CRYSOL package for structural validation ${ }^{58}$. Modelling of the entire RPC5 C terminus (RPC5EXT) was performed using Ensemble Optimisation (EOM) analysis from the ATSAS package ${ }^{59}$ of the RPC5EXT SAXS data using the $q$-range $0<q<0.2 \AA^{-1}$. The determined tWHD1 and tWHD2 crystal structures were defined as rigid bodies in the RPC5 C-terminal sequence, with EOM analysis modelling the intervening 115 amino acid linker as dummy atoms, generating a pool of 10,000 random structural conformations from which the ensemble was selected to sample the continuous structural heterogeneity.

Cell culture. HEK293T cells (a kind gift from Dr Sebastien Guettler) were cultured in DMEM supplemented with $10 \%$ heat-inactivated FBS and $1 \%$ penicillin/streptomycin at $37^{\circ} \mathrm{C}$ in $5 \% \mathrm{CO}_{2}$. For transient knockdown, $20 \mathrm{nM}$ siRNA of either ONTARGETplus siRNA for RPC5 (Horizon Discovery) or AllStars negative control siRNA (Qiagen) was used per well. This was transfected using Lullaby transfection reagent (Oz Biosciences) as per the manufacturers' instructions. The sequences for each RPC5 siRNA are as follows: 5'-UGGAUAAGGCUGACGCCAA-3', 5'-GGGAGCA GAUUGCGCUGAA-3', 5'-CGACGAGACCAGCACGUAU-3', 5'-CCUCGAUGAC CUACGAUGA-3'. For transient overexpression of RPC5 (HA-tagged full-length $\Delta \mathrm{tWHD} 2$ or $\Delta \mathrm{C})$, DNA $(1.5 \mu \mathrm{g})$ was transfected in using Fugene HD transfection reagent (Promega) as per the manufacturers' instructions.

Antibodies. The following primary antibodies were used: POLR3A (ab96328, Abcam), POLR3B (ab137030, Abcam), POLR3D (ab86786, Abcam), POLR3E (ab134560, Abcam), HA-tag (ab9110, Abcam), GAPDH (MAB374, diluted 1:5000 for western blotting, Merck) and RPA40 (sc-374443, Santa Cruz). The following secondary antibodies were used: anti-rabbit IgG $(\mathrm{H}+\mathrm{L})$ DyLight $^{\mathrm{TM}} 8004 \times$ PEG conjugate (\#5151, Cell Signalling Technology) and anti-mouse IgG $(\mathrm{H}+\mathrm{L})$ DyLight $^{\mathrm{TM}} 680$ ( $\# 5470$, Cell Signalling Technology). All antibodies were used at a dilution of $1: 1000$, unless otherwise stated.

Co-immunoprecipitation and western blotting. HEK293T cells were seeded into $10 \mathrm{~cm}$ plates in the presence of siRNA. After $24 \mathrm{~h}$, they were subsequently transfected with RPC5 (HA-tagged full-length $\triangle \mathrm{tWHD} 2$ or $\triangle \mathrm{C}$ ) and maintained for a further $24 \mathrm{~h}$. Cells were lysed in RIPA buffer and co-immunoprecipitation was performed using Pierce ${ }^{\mathrm{TM}}$ anti-HA magnetic beads (Thermo Fisher Scientific). HA-tagged proteins were eluted from the beads through addition of NuPAGE ${ }^{\mathrm{TM}}$ LDS $4 \times$ sample buffer and boiling the samples for $10 \mathrm{~min}$. For whole-cell lysates, cells were lysed in RIPA buffer and then NuPAGE ${ }^{\mathrm{TM}}$ LDS $4 \times$ sample buffer (Thermo Fisher Scientific) plus NuPAGE ${ }^{\mathrm{TM}} 10 \times$ sample reducing agent (Thermo Fisher Scientific) was added before being boiled for $5 \mathrm{~min}$. SDS-PAGE was subsequently performed on the lysates in $4-12 \%$ Bis-Tris protein gels, transferred to nitrocellulose membrane, blocked for $1 \mathrm{~h}$ in $5 \%$ milk/Tris-buffered saline/0.1\% Tween 20 and probed with primary antibody overnight at $4{ }^{\circ} \mathrm{C}$. Secondary antibodies were incubated for $1 \mathrm{~h}$ at room temperature in the dark and detected using the Odyssey-CLx fluorescence imaging system (LI-COR Biosciences). All uncropped gel images are available in the source data file.

Cycloheximide chase assay. HEK293T cells were seeded into six-well plates in the presence of siRNA. After $24 \mathrm{~h}$, they were subsequently transfected with either RPC5 (HA-tagged full length or $\Delta \mathrm{C}$ ) and maintained for a further $24 \mathrm{~h}$. Cycloheximide was then added at a concentration of $300 \mu \mathrm{g} / \mathrm{ml}$ and cells lysed at regular time points (every $2 \mathrm{~h}$, up to a maximum of $8 \mathrm{~h}$ ) using RIPA buffer and lysates were analysed via western blotting, as previously stated. All uncropped gel images are available in the Source Data file.

Reporting summary. Further information on research design is available in the Nature Research Reporting Summary linked to this article.

\section{Data availability}

The electron density reconstructions and final model were deposited with the Electron Microscopy Data Base under accession code number EMD-11904 and with the Protein Data Bank (PDB) under accession code 7AST. The PDB accession numbers for the atomic coordinates and structure factors of the RPC5EXT tWHD1 and tWHD2 crystal structures reported in this paper are 7ASU and 7ASV, respectively. The RNA Pol models used in this study are available from PDB under accession codes 5FYW, 5W66, 6EU0, $6 \mathrm{EU} 2$ and $6 \mathrm{EU} 3$. Source data are provided with this paper.

Received: 30 September 2020; Accepted: 20 November 2020; Published online: 17 December 2020

\section{References}

1. Cramer, P. et al. Structure of eukaryotic RNA polymerases. Annu. Rev. Biophys. 37, 337-352 (2008).

2. Vannini, A. \& Cramer, P. Conservation between the RNA Polymerase I, II, and III transcription initiation machineries. Mol. Cell 45, 439-446 2012).

3. Vorlander, M. K., Khatter, H., Wetzel, R., Hagen, W. J. H. \& Muller, C. W. Molecular mechanism of promoter opening by RNA polymerase III. Nature 553, 295-300 (2018).

4. Abascal-Palacios, G., Ramsay, E. P., Beuron, F., Morris, E. \& Vannini, A. Structural basis of RNA polymerase III transcription initiation. Nature 553, 301-306 (2018)

5. White, R. J. Transcription by RNA polymerase III: more complex than we thought. Nat. Rev. Genet. 12, 459-463 (2011)

6. Filer, D. et al. RNA polymerase III limits longevity downstream of TORC1. Nature, https://doi.org/10.1038/nature25007 (2017).

7. Thiffault, I. et al. Recessive mutations in POLR1C cause a leukodystrophy by impairing biogenesis of RNA polymerase III. Nat. Commun. 6, 7623 (2015).

8. Bernard, G. et al. Mutations of POLR3A encoding a catalytic subunit of RNA polymerase Pol III cause a recessive hypomyelinating leukodystrophy. Am. J. Hum. Genet. 89, 415-423 (2011).

9. Tetreault, M. et al. Recessive mutations in POLR3B, encoding the second largest subunit of Pol III, cause a rare hypomyelinating leukodystrophy. Am. J. Hum. Genet. 89, 652-655 (2011).

10. Saitsu, H. et al. Mutations in POLR3A and POLR3B encoding RNA polymerase III subunits cause an autosomal-recessive hypomyelinating leukoencephalopathy. Am. J. Hum. Genet. https://doi.org/10.1016/j. ajhg.2011.10.003 (2011).

11. Dauwerse, J. G. et al. Mutations in genes encoding subunits of RNA polymerases I and III cause Treacher Collins syndrome. Nat. Genet. 43, 20-22 (2011).

12. Schaefer, E. et al. Autosomal recessive POLR1D mutation with decrease of TCOF1 mRNA is responsible for Treacher Collins syndrome. Genet. Med. 16, 720-724 (2014).

13. Paolacci, S. et al. Specific combinations of biallelic POLR3A variants cause Wiedemann-Rautenstrauch syndrome. J. Med. Genet. 55, 837-846 (2018).

14. Wambach, J. A. et al. Bi-allelic POLR3A loss-of-function variants cause autosomal-recessive Wiedemann-Rautenstrauch syndrome. Am. J. Hum. Genet. 103, 968-975 (2018).

15. Ogunjimi, B. et al. Inborn errors in RNA polymerase III underlie severe varicella zoster virus infections. J. Clin. Invest. 127, 3543-3556 (2017).

16. Carter-Timofte, M. E., Hansen, A. F., Christiansen, M., Paludan, S. R. \& Mogensen, T. H. Mutations in RNA polymerase III genes and defective DNA sensing in adults with varicella-zoster virus CNS infection. Genes Immun, https://doi.org/10.1038/s41435-018-0027-y (2018).

17. Chiu, Y.-H., Macmillan, J. B. \& Chen, Z. J. RNA polymerase III detects cytosolic DNA and induces type I interferons through the RIG-I pathway. Cell 138, 576-591 (2009).

18. Ablasser, A. et al. RIG-I-dependent sensing of poly(dA:dT) through the induction of an RNA polymerase III-transcribed RNA intermediate. Nat. Immunol. 10, 1065-1072 (2009).

19. Wang, Z. \& Roeder, R. G. Three human RNA polymerase III-specific subunits form a subcomplex with a selective function in specific transcription initiation. Genes Dev. 11, 1315-1326 (1997).

20. Vos, S. M., Farnung, L., Urlaub, H. \& Cramer, P. Structure of paused transcription complex Pol II-DSIF-NELF. Nature 560, 601-606 (2018).

21. Vos, S. M. et al. Structure of activated transcription complex Pol II-DSIF-PAFSPT6. Nature 560, 607-612 (2018).

22. Blombach, F. et al. Archaeal TFEalpha/beta is a hybrid of TFIIE and the RNA polymerase III subcomplex hRPC62/39. Elife 4, e08378 (2015).

23. Hoffmann, N. A. et al. Molecular structures of unbound and transcribing RNA polymerase III. Nature 528, 231-236 (2015).

24. Plaschka, C. et al. Transcription initiation complex structures elucidate DNA opening. Nature 533, 353-358 (2016).

25. Nogales, E., Louder, R. K. \& He, Y. Structural insights into the eukaryotic transcription initiation machinery. Annu. Rev. Biophys. 46, 59-83 (2017).

26. He, Y. et al. Near-atomic resolution visualization of human transcription promoter opening. Nature 533, 359-365 (2016).

27. Han, Y. et al. Structural mechanism of ATP-independent transcription initiation by RNA polymerase I. Elife 6, https://doi.org/10.7554/eLife.27414 (2017).

28. Sadian, Y. et al. Molecular insight into RNA polymerase I promoter recognition and promoter melting. Nat. Commun. 10, 5543 (2019).

29. Engel, C. et al. Structural basis of RNA polymerase I transcription initiation. Cell 169, 120-131 e122 (2017).

30. Sadian, Y. et al. Structural insights into transcription initiation by yeast RNA polymerase I. EMBO J. 36, 2698-2709 (2017).

31. Pilsl, M. \& Engel, C. Structural basis of RNA polymerase I pre-initiation complex formation and promoter melting. Nat. Commun. 11, 1206 (2020). 
32. Lydeard, J. R., Schulman, B. A. \& Harper, J. W. Building and remodelling Cullin-RING E3 ubiquitin ligases. EMBO Rep. 14, 1050-1061 (2013).

33. Daoud, H. et al. Mutations in POLR3A and POLR3B are a major cause of hypomyelinating leukodystrophies with or without dental abnormalities and/ or hypogonadotropic hypogonadism. J. Med. Genet. 50, 194-197 (2013).

34. Gauquelin, L. et al. Clinical spectrum of POLR3-related leukodystrophy caused by biallelic POLR1C pathogenic variants. Neurol. Genet. 5, e369 (2019).

35. Potic, A., Brais, B., Choquet, K., Schiffmann, R. \& Bernard, G. 4H syndrome with late-onset growth hormone deficiency caused by POLR3A mutations. Arch. Neurol. 69, 920-923 (2012).

36. Shimojima, K. et al. Novel compound heterozygous mutations of POLR3A revealed by whole-exome sequencing in a patient with hypomyelination. Brain Dev. 36, 315-321 (2014).

37. Terao, Y. et al. Diffuse central hypomyelination presenting as $4 \mathrm{H}$ syndrome caused by compound heterozygous mutations in POLR3A encoding the catalytic subunit of polymerase III. J. Neurol. Sci. 320, 102-105 (2012).

38. Carter-Timofte, M. E. et al. Varicella-zoster virus CNS vasculitis and RNA polymerase III gene mutation in identical twins. Neurol. Neuroimmunol. Neuroinflamm. 5, e500 (2018).

39. Walker-Kopp, N. et al. Treacher Collins syndrome mutations in Saccharomyces cerevisiae destabilize RNA polymerase I and III complex integrity. Hum. Mol. Genet. 26, 4290-4300 (2017).

40. Ran, F. et al. Genome engineering using the CRISPR-Cas9 system. Nat. Protoc. 8, 2281-2308 https://doi.org/10.1038/nprot.2013.143 (2013).

41. Dignam, J. D., Martin, P. L., Shastry, B. S. \& Roeder, R. G. Eukaryotic gene transcription with purified components. Methods Enzymol. 101, 582-598 (1983).

42. Zheng, S. Q. et al. MotionCor2: anisotropic correction of beam-induced motion for improved cryo-electron microscopy. Nat. Methods 14, 331-332 (2017).

43. Rohou, A. \& Grigorieff, N. CTFFIND4: fast and accurate defocus estimation from electron micrographs. J. Struct. Biol. 192, 216-221 (2015).

44. Grant, T., Rohou, A. \& Grigorieff, N. cisTEM, user-friendly software for single-particle image processing. Elife 7, https://doi.org/10.7554/eLife.35383 (2018).

45. Zivanov, J. et al. New tools for automated high-resolution cryo-EM structure determination in RELION-3. Elife 7, https://doi.org/10.7554/eLife.42166 (2018).

46. Punjani, A., Rubinstein, J. L., Fleet, D. J. \& Brubaker, M. A. cryoSPARC: algorithms for rapid unsupervised cryo-EM structure determination. Nat. Methods, https://doi.org/10.1038/nmeth.4169 (2017).

47. Kelley, L. A., Mezulis, S., Yates, C. M., Wass, M. N. \& Sternberg, M. J. The Phyre2 web portal for protein modeling, prediction and analysis. Nat. Protoc. 10, 845-858 (2015)

48. Pettersen, E. F. et al. UCSF Chimera-a visualization system for exploratory research and analysis. J. Comput. Chem. 25, 1605-1612 (2004).

49. Emsley, P., Lohkamp, B., Scott, W. G. \& Cowtan, K. Features and development of Coot. Acta Crystallogr. D. Biol. Crystallogr. 66, 486-501 (2010).

50. Adams, P. D. et al. PHENIX: a comprehensive Python-based system for macromolecular structure solution. Acta Crystallogr. D. Biol. Crystallogr. 66, 213-221 (2010).

51. Boissier, F., Dumay-Odelot, H., Teichmann, M. \& Fribourg, S. Structural analysis of human RPC32 beta-RPC62 complex. J. Struct. Biol. 192, 313-319 (2015).

52. Jones, D. T. Protein secondary structure prediction based on position-specific scoring matrices. J. Mol. Biol. 292, 195-202 (1999).

53. Soding, J., Biegert, A. \& Lupas, A. N. The HHpred interactive server for protein homology detection and structure prediction. Nucleic Acids Res. 33, W244-W248 (2005).

54. Heinig, M. \& Frishman, D. STRIDE: a web server for secondary structure assignment from known atomic coordinates of proteins. Nucleic Acids Res. 32, W500-W502 (2004).

55. Rambo, R. P. \& Tainer, J. A. Characterizing flexible and intrinsically unstructured biological macromolecules by SAS using the Porod-Debye law. Biopolymers 95, 559-571 (2011).

56. Svergun, D. I. Restoring low resolution structure of biological macromolecules from solution scattering using simulated annealing. Biophys. J. 76, 2879-2886 (1999).

57. Volkov, V. V. \& Svergun, D. I. Uniqueness of ab initio shape determination in small-angle scattering. J. Appl. Crystallogr. 36, 860-864 (2003).
58. Svergun, D., Barberato, C. \& Koch, M. H. J. CRYSOL - a program to evaluate $\mathrm{x}$-ray solution scattering of biological macromolecules from atomic coordinates. J. Appl. Crystallogr. 28, 768-773 (1995).

59. Tria, G., Mertens, H. D. T., Kachala, M. \& Svergun, D. I. Advanced ensemble modelling of flexible macromolecules using X-ray solution scattering. IUCrJ 2, 207-217 (2015)

\section{Acknowledgements}

We thank all members of the Vannini and Engel groups for discussion throughout this study. We thank Tino Pleiner for discussion, Ilya Komarov for help with nuclear fractionation, Andrea Bleckmann and Juan Rodriguez Alcázar for assistance with confocal microscopy and Astrid Bruckmann for mass spectrometry. We also thank Rebecca Thompson and the Astbury Biostructure Laboratory, University of Leeds for human Pol III imaging. In addition, we thank Ruth Peat and the Cell Services Scientific Technical Platform at the Francis Crick Institute for large-scale POLR1C-GFP cell growth. C.E. acknowledges funding by DFG's Emmy-Noether Programme (EN 1204/1-1) and support by the collaborative research centre 960 (SFB960/TP-A8). This work was funded by the Cancer Research UK Programme Foundation (CR-UK C47547/A21536) and a Wellcome Trust Investigator Award (200818/Z/16/Z) to A.V.

\section{Author contributions}

C.E. and P.G. designed and performed genome-editing experiments. P.G. created the stable POLR1C-sfGFP HeLa cell line. C.E., M.P. and J.L.D. performed initial small-scale purifications of human Pol III. J.L.D. optimized suspension cultivation of RPAC1-GFP cells, carried out transcription assays and confocal microscopy. G.A.-P. and E.P.R. performed large-scale purification of human Pol III and prepared samples for EM analysis, and collected cryo-EM data. F.B. carried out cryo-EM sample preparation, screening and sample collection, and E.M helped with preliminary evaluation of data. E.P.R. performed cryo-EM data processing. G.A.-P. performed X-ray crystallography experiments and analysed the data. J.G. collected SAXS data. E.P.R. and G.-A.P. analysed SAXS data. H.K. performed experiments in living cells. G.A.-P., E.P.R., H.K. and A.V. interpreted the data. A.V wrote the manuscript with input from all the authors. C.E. and A.V. designed and supervised research.

\section{Competing interests}

The authors declare no competing interests.

\section{Additional information}

Supplementary information is available for this paper at https://doi.org/10.1038/s41467020-20262-5.

Correspondence and requests for materials should be addressed to C.E. or A.V.

Peer review information Nature Communications thanks the anonymous reviewer(s) for their contribution to the peer review of this work. Peer reviewer reports are available.

Reprints and permission information is available at http://www.nature.com/reprints

Publisher's note Springer Nature remains neutral with regard to jurisdictional claims in published maps and institutional affiliations.

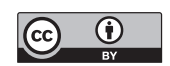

Open Access This article is licensed under a Creative Commons Attribution 4.0 International License, which permits use, sharing, adaptation, distribution and reproduction in any medium or format, as long as you give appropriate credit to the original author(s) and the source, provide a link to the Creative Commons license, and indicate if changes were made. The images or other third party material in this article are included in the article's Creative Commons license, unless indicated otherwise in a credit line to the material. If material is not included in the article's Creative Commons license and your intended use is not permitted by statutory regulation or exceeds the permitted use, you will need to obtain permission directly from the copyright holder. To view a copy of this license, visit http://creativecommons.org/ licenses/by/4.0/.

(C) The Author(s) 2020 